\title{
Police Disruption and Performance: Evidence from Recurrent Redeployments within a City*
}

\author{
Giovanni Mastrobuoni ${ }^{\dagger}$
}

March, 2019

\begin{abstract}
Little is known about the mechanisms through which additional police resources reduce crime. Criminals may perceive the increased risk of being caught and be deterred, or they may be arrested at higher rates; preventing them from committing additional crimes while incarcerated. This study sheds light on the mechanisms using individual-level crime data. It documents that shift changes of police patrols disrupt police activity and lower the likelihood of clearing crimes and arresting perpetrators by about 30 percent. Strong evidence of repeat offending implies that arrests lead to subsequent incapacitation. The aggregate-level relationship between crime rates and clearance rates is in line with sizable incapacitation effects.
\end{abstract}

Keywords: police, crime, incapacitation, deterrence, arrests, deployment, quasiexperiment, shift changes

JEL classification codes: K42; H00

${ }^{*}$ I would like to thank the Police Chief of Milan (Questore di Milano) for providing the data, as well as Mario Venturi and his staff for sharing their knowledge on robberies and policing. I would also like to thank Orley Ashenfelter, Jordi Blanes i Vidal, Phil Cook, Matthew Freedman, Lance Lochner, Marco Manacorda, Emily Owens, David Rivers, Ben Vollard, and seminar participants at the University of Surrey, Collegio Carlo Alberto, Cornell University, Université du Québec à Montréal, Queen Mary University, Western University, the Al Capone workshop, and the 4th Transatlantic Workshop on the Economics of Crime for their comments.

${ }^{\dagger}$ Collegio Carlo Alberto and University of Torino giovanni.mastrobuoni@carloalberto.org 


\section{Introduction}

The United States and the European Union both spend about one percent of their GDP on public police services. Police expenditures represent 55 percent of all government expenditures on public order and safety, with fire protection services, law courts, prisons, and $R \& D$ absorbing the rest of the budget.1

Whether the money is well spent depends on the marginal benefits of an extra dollar allocated to police resources. In an attempt to measure such benefits researchers have long examined the relationship between policing and crime. Yet, there is still surprisingly little consensus on whether and how more policing reduces crime (see Carriaga and Worrall, 2015).

In recent years empirical economists have contributed to this literature producing compelling evidence on a negative relationship between police levels and crime. See, among others, Corman and Mocan (2000), Evans and Owens (2007), Levitt (1997), and Chalfin and McCrary (2018) ? $^{2}$ The mechanism behind this relationship is still unclear, and has recently been called a "black box" (Cook et al., 2011, Durlauf and Nagin, 2011).

A better understanding of the mechanisms is crucial to determine the benefits of policing, as the two channels that could be at work, incapacitation and deterrence, have different implications for public spending. More police forces might help clearing more crimes, which would lead to more arrests and convictions, hence incapacitating arrested individuals from committing other crimes, for as long as they are in custody. A necessary condition for the presence of incapacitation is that additional policing increases the likelihood that after committing an offense people are put in custody. This generates additional expenditures for law courts and prisons, which have to be factored in when evaluating the cost of policing.

The presence of additional police might also lead to an increase in the perceived risk of arrest, deterring criminals from committing the crime altogether. Deterrence, which has been the focus of seminal contributions in the economics of crime literature (see Becker, 1968, Ehrlich, 1973), has the attractive feature of avoiding additional expenditures in law courts and prisons.

Since incapacitation and deterrence are so intertwined it has been challenging to convincingly separate one from the other. This paper moves one step back. Even though both

\footnotetext{
${ }^{1}$ See Kyckelhahn $(2011)$ and the "Government expenditure on public order and safety" report published by EUROSTAT http://ec.europa.eu/eurostat/.

${ }^{2}$ In contrast, a large criminological literature has generally failed to find significant impacts of police on crime, even in quasi-experimental studies (see Sherman, 2002, Skogan and Frydl, 2004, for an overview of such evidence). Sherman and Weisburd (1995) represents a notable exception.
} 
mechanisms hinge on how additional police patrolling changes the likelihood of clearing crimes (to generate deterrence and incapacitation additional policing has to increase the perceived and the actual risk of arrest, respectively), there is very little evidence on such a mechanism. $3^{3}$ The main empirical challenge when dealing with the mechanism has been that clearances are equilibrium outcomes in a game involving police officers and criminals (Cook, 1979). $!^{4}$

The primary aim of this study is to provide micro-level evidence on whether more policing increases the likelihood that a crime is cleared. This is not a settled issue, as many criminologists would argue that prompt police presence has little impact on clearances (see, among others, Sherman, 2013, Skogan et al., 2004, Weisburd and Eck, 2004).

I use the universe of commercial robberies in Milan between January 2009 and June 2011 together with quasi-experimental variation in policing to deal with endogeneity issues: Italian cities are patrolled by two police forces, and each force has exclusive control over specific quadrants of the city. These quadrants rotate every shift change (about every six hours), forcing police cars to make arduous and disruptive trips across the city. The evidence as well as informal conversations with police officers reveal a link between such disruptions and clearances, especially when the diversion is severe and police cars have to travel long distances.

Robberies that take place far away from the police headquarters, which is where police cars start and end their shift, are considerably less likely to be cleared (-30 percent), but only around shift changes.

Do criminals exploit the timing of shift changes? Section 5 addresses in great detail the response of criminals. The analysis is based on the choice of time and location of robberies, on the selection of robbers during shift change periods, and on the dynamic behavior of robbers. There is no evidence that during shift changes robbers are more likely to target businesses which are located away from the headquarters, and therefore are less likely to be patrolled. The institutional detail as well as the evidence suggests that the diversion is not salient enough to generate an endogenous response of criminals.

\footnotetext{
${ }^{3} \mathrm{~A}$ few papers have used clearance rates as a measure of productivity of police departments (Garicano and Heaton, 2010, Mas, 2006).

${ }^{4}$ About thirty years ago a few papers analyzed clearances (Carr-Hill and Stern, 1973, Craig, 1987 , Mathur, 1978, Thaler, 1977, Wolpin, 1978). Using simultaneous equations models with non-testable identification restrictions, most of these papers find support for the existence of both deterrence and incapacitation. In particular, in Thaler (1977) individual crime-level clearance rates, similar to the ones used in this study, are shown to respond strongly to changes in the number of police officers. The issue is that such deployment is likely to be endogenous. In the criminology literature little evidence is found of an effect of policing on clearance rates (Cordner, 1989, Skogan and Frydl, 2004), but again deployment of police forces is likely to be endogenous.
} 
This paper is related to recent studies that exploit changes in highly visible and predominantly static police deployment following terrorist attacks (Di Tella and Schargrodsky, 2004, Draca et al., 2011, Klick and Tabarrok, 2005, Machin and Marie, 2011). These are ideal conditions to measure deterrence, and all four papers observe localized and abrupt changes in crime rates.5 Focussing on a different but common type of policing, automobile patrolling, complements these studies ${ }^{6}$ The most closely related paper, Blanes i Vidal and Kirchmaier (2017), exploits exogenous variation in police response times, showing that increased response times lower the likelihood that a crime is solved and the perpetrators are put in custody. And as in Blanes i Vidal and Kirchmaier (2017), I find no evidence that criminals exploit potentially predictable policing patterns.

Finally, I discuss how the relationship between policing and clearances generates a peculiar pattern between crime and clearances. When more policing increases the likelihood of clearing and arresting offenders, and there are numerous repeat offenders, crime rates become inversely proportional to clearance rates, implying that the elasticity of crime with respect to policing equals the negative elasticity of clearance rates with respect to policing. Province level scatter plots of crime rates against clearance rates are consistent with important incapacitation effects.

\section{The Quasi-experiment}

Italy has two police forces, the Polizia and the Carabinieri that share the same functions and objectives, but are, by all means, two separate entities.7 Separate ministries oversee their activities and they have separate emergency telephone numbers (112 and 113). Figure 1) shows the location of the two headquarters, located in the very city center, a few hundred yards from each other. The map displays the exact location of each commercial robbery that happened in Milan by the intervening force. Each "square" and each "plus" sign represents a different victimized commercial business that has been (quasi-randomly) assigned to, respectively, the Carabineri and to the Polizia, according to the following rule.

\footnotetext{
${ }^{5} \mathrm{~A}$ set of studies in criminology uses random changes in patrols to test the effectiveness of police forces. Skogan and Frydl (2004) review the criminology literature on the effectiveness of policing. The studies that evaluate the effect of policing on crime generally find that crime spikes during strikes. But strikes are perfectly predictable and known, and when they happen most of the change in crime seems to be driven by the sudden and complete lack of deterrence.

${ }^{6}$ According to recent policing statistics nearly 7 in 10 local police officers had regular patrolling duties, and almost all U.S. local police departments use regularly scheduled automobile patrols (Reaves, 2011).

${ }^{7}$ The Carabinieri were the royal police force, the gendarmerie, and despite the 1945 referendum that ended the monarchy in favor of the republic, they were not dismantled.
} 
Each force is responsible for keeping law and order in a different part of the city. For police deployment purposes the city is divided into three areas, North-West, North-East, and South; the Southern area is the largest, covering between 40 and 50 percent of the city and 43 percent of the robberies (another 34 percent of the robberies happen in the North-Eastern part of the city and the rest in the North-Western part). At any given point in time one area is under the control of the Carabinieri, and two under the control of the Polizia.

Such assignments rotate clockwise about every six hours, in concert with shift changes. The " 911 " operators forward the call to the assigned police force depending on the exact time of the call and the exact location of the crime. Incoming patrols operate up to the hour, and outgoing ones operate past the hour. At any given point in time either the incoming or the outgoing car is formally on duty, which sets a limit to the total number of active patrols which are ready to arrest culprits. In order to reduce the complexity of the assignments procedure, there are no attempts to accommodate delays. 8

Police patrols that are finishing their shift head for the headquarters, while police patrols that are starting their shift drive from the headquarters towards the area they have been assigned. With two forces, three areas, and four 6-hour shifts within a given day, the Carabinieri cover the same area during the same 6-hour shift only every three days. This induces quasi-random variation in the days of the month, days of the week, and 6-hour shift in the geographic coverage of police forces. Inside each area there are about 7 to 10 cars that cover around 120 square kilometers (40 square miles). The rotation mechanism is clearly visible in Figure 2. Each panel represents a map of robberies in a day/shift combination. Since there are three areas and four shifts there are a total of 12 combinations.? In days of type 1 (top row) the Carabinieri start patrolling the NorthWestern part of the city at midnight, move to the North-Eastern part at 7am, then move to the Southern part at 1pm, and finish the day back in the North-Eastern neighborhoods. The other two types of days the Carabinieri start the rotation in the other two sectors. The Polizia follows specular moves.

It is obvious that the rotation induces time-consuming trips across the city, and institutional rules try to reduce the potential for disruption. The most important one prescribes that changes should occur directly on the street at the hour sharp. But in order to have

\footnotetext{
${ }^{8}$ To assess the importance of the lack of coordination across the two police forces and the resultant lack of continuity of control over a territory, later I exploit the fact that the Polizia retains control in one of the three rotating areas.

${ }^{9}$ Outliers in the recurrent pattern are driven by officers who are part of the smaller non-rotating Polizia or Carabinieri forces. The neighborhood police forces, the mobile forces, and the motor-bikers follow a different shift: $8 \mathrm{am}-2 \mathrm{pm}$ and $2 \mathrm{pm}-8 \mathrm{pm}$.
} 
the shift changes operate on the streets each forces requires twice the number of active police cars (one for the outgoing force and one for the incoming one). Unfortunately Milan police union members complain that for about 50 percent of the incoming cars there are no outgoing cars available (Biondini, 2011, Editorial Office, 2011, Garofalo, 2013, see). When an extra car is missing the shift has to be performed inside the headquarters, as officers working in subsequent shifts share the same police car. The Polizia calls them "car on car" shift changes (macchina su macchina). Car availability is on a first come first serve basis.10 Since the sequence of the incoming forces is unpredictable, so is the location that is going to be subject to a "car on car" shift change.

The degree of disruption depends on the time it takes to drive from the headquarters to the site of potential victims. While the switching of the crews inside the headquarters is likely to be quick, Google Map estimates that it takes on average 15 minutes to drive from the assigned neighborhood to the headquarters (see Table 1).

Summing up, shift changes may disrupt police patrolling, especially if there is an insufficient number of police cars. Whenever the shift change happens according to the law the number of visible police cars may actually increase, and since criminals cannot distinguish active from inactive patrols, shift changes might actually increase deterrence. When, instead, a shift change happens inside the headquarters, for a few minutes the neighborhood might be completely unpatrolled. Delays of either the incoming (the patrols might be in the middle of a task) or the outgoing cars (the car might be broken, or the officers might be late, or, more simply, streets might be congested), could either increase deterrence or additionally disrupt policing depending on the availability of overlapping cars.11

I use the exact time of the robbery and the exact distance from the headquarters measured in driving time to predict whether the incoming or the outgoing police patrol could have reached the victimized commercial business on time. Information about the switching of the areas of deployment, as well as on the exact time of robberies and the exact distance between robbed businesses and the police headquarters, allows me to estimate the effect of disrupting police patrolling on a binary variable measuring whether the robbery has been solved (meaning that at least one arrest has been made). 12

\footnotetext{
${ }^{10}$ According to private conversations I had with police officers, the location of "car on car" shift changes are not chosen strategically.

${ }^{11}$ According to a contractual agreement the extra minutes spent on the street during overlapping police patrolling are unpaid.

${ }^{12}$ According to the Milan Polizia clearing a robbery means that at least one robber has been identified, which leads to an arrest. But most times the identified offender chooses to collaborate with the policeidentifying his fellow offenders-to receive sentence reductions. For this reason I use clearances and arrests
} 
Crime reductions that are driven by localized changes in policing, whether driven by deterrence or incapacitation, may generate not just immediate but also cumulative effects, with gradual, spatially diffused, and potentially hard to identify reductions in the amount of crime. 13

The advantage of measuring the relationship between clearances (in essence arrests) and policing, is that disruptions should have immediate effects that can be linked to specific locations, allowing for a more designated identification strategy.

\subsection{Main Threats to Identification}

The main identification threat is that the time of the shift changes is recurrent and thus predictable. The public is uniformed about the shift and rotation mechanism, yet it is hard to completely rule out the possibility that some professional robbers may be aware of it. What is unpredictable is whether there is a shortage of police cars, and when and where such shortage disrupts policing.

An additional threat is that the shifts happen always at the same time, and those times may have features that are correlated with police productivity: businesses may be closing, traffic may be heavy, it may still be dark around 7 am or already dark at $7 \mathrm{pm}$. While these feature can be measured and be controlled for, it could also be that police officers are tired from finishing their shift, or are not fully operational at the very beginning of their shift.

To address these concerns it is important not just to use the time variation driven by shift changes, but to interact such variation with the distance from the police headquarters. The advantage of this difference-in-differences strategy is that it controls for any unobserved factors that influence the optimal timing of robberies (like those mentioned in the previous paragraph) as long as these do not depend on the distance from the headquarters (see Section 5).

Moreover, such interactions are ideal tests for selection. An excess mass of robberies against commercial business that are located far from the headquarters during a shift change would be evidence that robbers exploit shift changes, and that shift changes generate negative deterrence. The formal test is a difference-in-differences in the number of robberies depending on location (below/above median distance from the headquarters)

\footnotetext{
as synonymous.

${ }^{13}$ For example, the Online Figure 14 shows that groups of robbers tend to operate in selected parts of the city. These clusters tend to be quite large, as robbers sometimes operate across the entire city. This implies that arresting robbers in one part of the city would lower crimes in many more locations.
} 
and time (shift change status) of the robbery. This is the simplest and yet most powerful test for whether criminals are aware of the vulnerability of law enforcement during shift changes.

The data also allow for a whole battery of additional tests that for brevity can be found in the Online Appendix A.3. Selection that is driven by knowledgable and smart robbers would typically produce positive answers to some of the following questions: Is the modus operandi of robberies that happen during shift changes different from all the others? ${ }^{14}$ Are able robbers, defined as those who are more unpredictable and, therefore, more successful, more likely to target businesses during shift changes? Does controlling for the experience of robbers, measured by the number of successful robberies, alter the results? Are robbers who happened to commit a robbery during a shift change (and thus might have learned about the deficiencies in policing) more likely to do so again in their subsequent robbery? Do the findings differ when focussing on robbers who for the first time happen to perform a robbery during a shift change, and therefore are less likely to have deliberately chosen such periods? These tests are increasingly able to detect whether at least some robbers are aware of the disruptive power of shift changes.

\section{Milan Crime Data}

The area under study, which comprises the municipality of Milan (Comune) as well as part of the smaller neighboring municipalities around it (Provincia) has a population of close to 1.5 million. The land area under study is close to 350 square kilometers (134 square miles) 15 Milan, like many historical European cities (e.g. Rome, Paris, London, etc.) has irregular city blocks and a highly chaotic network of streets.

For investigative purposes the anti-robbery Polizia department of Milan collects information on individual robberies and robbers (not yet for the other crimes). After each robbery, even those assigned to the Carabinieri, the Polizia collects all kinds of information about the perpetrators, the victim, the loot, etc ${ }^{16}$

The Polizia complements the information contained in patrol reports surveying the

\footnotetext{
${ }^{14}$ The most intuitive way to test whether there is such a selection is to perform a balance test depending on the time of the robbery. In Mastrobuoni (2011) I show that more able bank robbers tend to get larger hauls with specific modus operandi (e.g. they are more likely to use firearms). Thus, one would expect robberies that happen during shift changes to be associated with larger hauls.

${ }^{15}$ Aggregate crime rates and clearance rates show that within Italy the city does not represent an outlier (see Figure 10 .

${ }^{16}$ The Polizia force does not record the exact locations of police cars in every moment in time (such data would not just be difficult to store but also quite hard to analyze).
} 
victims, and collecting any available information that is recorded by nearby surveillance cameras. Their main purposes are i) to identify recurrent perpetrators in order to predict their future offenses, and ii) to provide prosecutors with forensic evidence. This method is known as predictive policing.

While in the absence of victimization surveys of commercial businesses exact victims' reporting rates cannot be computed, according to police investigations these are close to 100 percent. Evidence of this is based on criminals' confessions. Since most robbers are caught in flagrante delicto they have an incentive to plead guilty in order to receive a $1 / 3$ sentencing reduction (patteggiamento). According to the Polizia only in one instance did an arrestee confess a robbery that had not been reported (later the business owner acknowledged that he had not having reported the crime). Businesses might be aware that the only way to increase police patrolling in their neighborhood is by reporting the crime 17

\subsection{Summary Statistics}

I have been given access to a subset of the variables used by the Polizia to predict the crimes between January 2008 and June 2011. The many variables that describe in great detail the physical appearance of robbers were not added to the dataset, while those that describe the modus operandi of the robbers were added.

In the data each observation is a separate robbery, and 353 happen within 15 minutes of a shift change. The remaining 1,814 do not. The 16 percent of robberies that fall within those 30 minute periods are higher than what a uniform distribution would predict, which is going to be discussed in great detail when testing for deterrence (Section 5).

The summary statistics by shift change status are shown in Table 1. Shift change status is a $0 / 1$ variable that measures the change in shift 15 minutes before up to 15 minutes after the beginning of a shift; for example, 6.45am-7.15am around the start of the $7 \mathrm{am}-1 \mathrm{pm}$ shift. The likelihood of clearing a robbery (by means of an arrest) during a shift change is 9.1 percent, while it is 14.8 percent during the rest of the day. The third group of columns shows that this raw difference is significant at the 1 percent level. The only other variables that differ significantly are the fraction of robberies that happen during the 30 minutes that precede the shops' closing time. Since the exact opening hours of each business are not known, I use two proxies for the closing times. I divide businesses into 23 homogenous categories and take the maximum and the 90 th percentile

\footnotetext{
${ }^{17}$ On top of this, businesses often need a police report for insurance purposes.
} 
of the observed time of the robberies. 18 While a few businesses close around the $7 \mathrm{pm}$ shift change (bakeries and jewelers), most close around 8pm, which is why the difference tends to be negative. When exploiting the differences between business that are far away or close to the headquarters these differences disappear.

The Polizia uses information taken from surveillance cameras together with very detailed descriptions by the victims about the robbers to link offenders across robberies. The Serial robbers variable identifies robbers who have been linked (70 percent of robberies are linked to such serial robbers). Figure 3 shows a screen-shot of the software used to reconstruct such series. The variable "Number of the series" indexes the robberies that are linked with each other in a chronological manner. Such number is later used as a proxy for experience.

The Police variable indicates whether the Polizia handled that particular robbery. While the city is divided into 3 parts and the Polizia is responsible for 2 parts, the fraction of robberies that is handled by the Polizia is slightly larger than expected (73 against 67 percent). Before 2010 the Polizia was using a predictive policing software called Keycrime to catch serial robbers, a software which was later shared with the Carbinieri. A few additional variables describe the modus operandi of the robberies, as well as the value of the stolen loot. Notice that the variables that are assumed to signal ability, like loot, or the use of firearms (see Mastrobuoni, 2011) do not seem to vary depending on the shift change status, indicating that more able robbers are not targeting those periods (additional tests for deterrence, based on the entire distribution of the loot are shown in Section 5).

\section{The Effect of Disrupted Policing on Clearance Rates}

\subsection{Simple Differences}

The simplest way to estimate the effect of a shift change on clearing a robbery is to compute the difference between the probability of clearing a robbery during a shift change and the probability of clearing a robbery during the rest of the day.

I take 15 minute periods on each side of the four shift changes $T_{j}, j=1, \ldots, 4$ (later I also define the intervals based on Google's estimated distance between the location of the robbery and the headquarters). The first row in the summary statistics Table 1 shows that the probability of clearing a robbery (the clearance rate) is equal to 9.1 percent during

\footnotetext{
${ }^{18}$ The Online Appendix Table 9 shows the individual closing times.
} 
shift change periods and equal to 14.8 percent otherwise (as in the Summary statistics table). Such simple difference, estimated using a linear probability model, is significant at the 1 percent level.

But such difference might be driven by an underlying difference in clearance rates that the simple difference is unable to capture. In order to capture the underlying evolution of clearances one can estimate the effect on clearing of robbery $n$ perpetrated by the group of offenders $i$ using the following regression function:19

$$
Y_{i, n}=\alpha+\delta I\left(\min _{j}\left|t_{i, n}-T_{j}\right| \leq 15^{\prime}\right)+f\left(t_{i, n}\right)+x_{i, n}^{\prime} \beta+\epsilon_{i, n}
$$

where $I\left(\min _{j}\left|t_{i, n}-T_{j}\right| \leq 15^{\prime}\right)$ indicates whether the robbery happened within 15 minutes from a shift change; and, most importantly, $f\left(t_{i, n}\right)$ measures the underlying daily evolution of clearance rates. The other regressors $x_{i, n}$ control for observed characteristics of robbers and robberies. Given that the time of the day repeats itself every 24 hours this is the ideal setup to model $f\left(t_{i, n}\right)$ using periodic functions. There is a large literature in mathematics and in statistics on using series of sines and cosines, infinite and truncated Fourier series, to approximate any smooth function. ${ }^{20}$ Since time repeats itself in cycles such approximations are even more valuable 21

The underlying evolution of the probability of clearing a case becomes a function of sines and cosines $f(t)=\sum_{j=1}^{k}\left(\gamma_{0 j} \cos \left(j \times 2 \pi H_{i, n}\right)+\gamma_{1 j} \sin \left(j \times 2 \pi H_{i, n}\right)\right)$, where $H_{i, n}$ indicates the time of day standardized to lie between 0 (midnight) and 1 (one minute before midnight). Based on cross validation the optimal choice for $k$ is equal to $22^{22}$ $f\left(t_{i, n}\right)$ is also going to be estimated either using more common simple polynomials in time or the cubic spline function.

When estimating the difference-in-differences model, the shift change dummy is interacted with the distance from the headquarters. Distance is measured in driving time according to Google, and is dichotomized based on whether such time is below or above the median time, equal to 15 minutes. Such a difference-in-differences strategy controls

\footnotetext{
${ }^{19} \mathrm{All}$ the regression are estimated using least squares regressions and clustering the standard errors by group of offenders $i$.

${ }^{20} \mathrm{~A}$ weighted trigonometric series of sines and cosines is called a trigonometric polynomial of order $k$. Trigonometric polynomials have been used to approximate functions since Fourier's 1822 "The analytical theory of heat."

${ }^{21}$ Andrews (1991) shows that under some smoothness conditions a truncated Fourier series estimated using least squares converges to the true periodic function. While such smoothness conditions do not apply to clearance dummies the approximations turn out to be good.

${ }^{22}$ This choice serves a similar role here to the bandwidth parameter for non-parametric kernel estimations. See the Online Appendix Section A.1
} 
for any unobserved factors that might drive the choice of the time of the robbery, i.e. the business hours, the visibility conditions, and other strategies and constraints that depend on time.

The previous regression can easily be amended to compute placebo effects. Moving the intervals by $d$ multiples of 30 minutes from the true shift change periods the regression can estimate placebo shift change effects $\delta^{d}$ :

$$
Y_{i, n}=\alpha+\delta^{d} I\left(\min _{j}\left|t_{i, n}-T_{j}+d \cdot 30^{\prime}\right| \leq 15^{\prime}\right)+f\left(t_{i, n}\right)+x_{i, n}^{\prime} \beta+\epsilon_{i, n},
$$

where, for example, $d=0$ estimates the true effect $\delta^{0}=\delta$, while $d=2$ estimates the shift change effect one hour too early.

Instead of estimating the underlying evolution of clearances $f\left(t_{i, n}\right)$, one can use an event study design. Centering the time measured in hours around the closest shift change $j^{*}, e_{i, n}=t_{i, n}-T_{j^{*}}$, one can simply control for a series of half-hour event time periods. ${ }^{23}$ Since the shortest shift is 5 hours long (7pm-12am) we define five 30' periods on each side of the shift changes. Excluding a one hour event time period on each side of the shift change interval the dummy variables in the regressions are 7 , corresponding to the shift change interval, and the shift change interval shifted by negative and positive 2.5, 2 , and 1.5 hours. Defining the set of 30 minute shifts $\mathrm{S}=\{-2.5,-2,-1.5,0,1.5,2,2.5\}$, the event study regression becomes:

$$
Y_{i, n}=\alpha+\sum_{s \in S} \beta^{s} I\left(-15^{\prime}<e_{i, n}+s \cdot 60^{\prime} \leq 15^{\prime}\right)+x_{i, n}^{\prime} \beta+\epsilon_{i, n}
$$

$\beta^{0}$ measures the difference in the probability of clearing a case within the 30 minute shift change period, and the two one-hour adjacent periods. ${ }^{24}$

The advantage of the event time model is that all the placebo coefficients $(s \neq 0)$ are estimated at once. If chance was driving the results, the coefficient $\beta^{0}$ (the true shift change period) would be similar to many other $\beta^{s}$ s. And, again, one can interact the shift change dummies with an above median distance from the headquarters dummy to estimate a difference-in-differences.

\footnotetext{
${ }^{23}$ Online Figure 16 shows the relationship between the time of the day and the event time.

${ }^{24}$ The results are robust to the exclusion of longer adjacent time intervals, while choosing a shorter baseline interval reduces the precision of the estimates leaving the size unchanged.
} 


\subsubsection{Results from The Event Study Design}

Starting with the last model, Table 2 shows the estimated coefficients of a linear probability model of a robbery being cleared modelled as in Equation $3{ }^{25}$ The coefficient on the Shift change interval (SCI) represents the difference between the likelihood of clearing a robbery that happened within 15 minutes of a shift change, and one that happened during the two adjacent one-hour time intervals.

Column 1 does not include additional covariates $x$, while Column 2 includes the two variables that failed the balance test. ${ }^{26}$ Given that the balance test was done only for the shift change periods, in Column 3 I also include the value of the stolen loot, a Polizia dummy, a south and a north-west dummy, year by month dummies, day of the week dummies, a firearm dummy, a knife dummy, a daylight dummy, whether the robbery is against a bank, and the average number of thefts that are committed within the same 30 minutes 27

Just before and after the shift changes clearance rates are equal to 13.6 percent, and drop by -4.5 percentage points during shift changes. The only other significant coefficient (at the 10 percent level) is the one related to the interval that follows by 2 and a half hours the shift changes. Adding the two variables that failed the randomization test leaves the shift change coefficient almost unchanged, and non of the other 30 minute period is statistically speaking different from zero. In line with the results from the randomization table when I control for all the additional variables the coefficient on the shift change period remains unchanged. Moreover, controlling for the additional regressors all the other coefficients are precisely estimated to be close to zero.

\subsubsection{Results from the Semi-Parametric Difference Design}

Rather than comparing the shift changes to nearby periods, one can use Equation 1 to compare them to their counterfactual evolution. As mentioned, the underlying evolution can be modelled using different semi-parametric methods, and the hypothesis can be further tested by generating placebo shift changes $\delta^{d}, d \neq 0$.

Controlling for the underlying evolution of clearances, Table 3 shows that using peri-

\footnotetext{
${ }^{25}$ Given that in column 1 the covariates are discrete and the model is saturated the conditional expectation functions can be properly parameterized as a the linear model. Using a probit model in all three specifications (Columns 1 to 3 ) the marginal effects are almost identical to the linear probability case.

${ }^{26}$ In line with the small differences shown in the balance test, having no other regressors or adding additional ones does not alter any of these results.

${ }^{27}$ Controlling, in addition, for the potentially endogenous predicted (by the victim) age of the robbers and perceived nationality of the robbers, as well as for their experience does not alter the results.
} 
odic functions for $f(t)$ the shift change effect is between -4.9 and -5.0 percentage points (similar to what was found in the event study design). Using a quartic in time or cubic splines the results are similar. ${ }^{28}$ Given the better fit and the previous discussion the rest of this study is going to estimate $f(t)$ using either the Fourier series, or the event study dummies (de facto the nearby time intervals).

The estimated true and placebo shift change coefficients $\delta^{d}$ with the corresponding 95 percent confidence intervals are shown in Figure 4. There is a clear reduction in the coefficients around the true shift change, and, in line with the results based on the event study, the only significant differences are around the shift changes. Notice that the negative coefficients at \pm 30 minutes might be driven by a misclassification of treatment, as at times it might take more than than 15 minutes to reach a given location. In the next Section I will exploit the exact time it takes to reach a victimized businesses. Moreover, since in placebo regressions the truly treated time interval contributes to the underlying evolution $(f(t))$, the placebo coefficients tend to be larger than zero.

\subsection{Differences-in-Differences Depending on the Distance from the HQ}

The previous estimates exploit only variation in time, and any unobserved heterogeneity that is correlated with time might bias the estimates. For example, the $7 \mathrm{pm}$ shift change happens before businesses close and around the time the sun goes down. Both factors might influence clearances. Since Polizia and Carabinieri patrols need to drive in and out of the headquarters, which are located in the city center, businesses located farther away from center are less protected.

Equations 2 and 3 are amended interacting the 30 minute time interval dummies with the above median and below median distance dummies. Columns 1 and 2 of Table 4 show the estimated effects when using the Fourier series and the event time strategy. The two set of estimates are very similar. During shift changes the reduction in the likelihood of clearing a case is indeed entirely driven by businesses that are located more than 15 minutes away from the headquarters (the median time to reach a victimized business according to Google Maps). For brevity I do not include all the interacted event time dummies, but all those that are not shown are precisely estimated to be close to zero. The difference between the shift change effects when the distance is above of below the

\footnotetext{
${ }^{28}$ The Online Figure 12 shows that except during the night time, where the sample size is quite small, the more flexible semi-parametric functions are similar to each other. The quartic in time, instead, tends to oversmooth the series.
} 
median has a p-value of 5 percent when using the more efficient semi-parametric Fourier series while it is close to 10 percent when using the less efficient non-parametric event time model.

Columns 3 and 4 test whether the lack of coordination between incoming and outgoing patrols is also taking place when the Polizia retains control over an area (I define such shifts as one in a "retained area"), ${ }^{29}$. There do not seem to be large differences based on whether the police forces retains control over an area, showing that lack of coordination happens also within the Polizia.

It follows from the differences-in-differences results by median time that using 15 minutes before and after to define the intention to treat status might not always be correct. In order to take the exact distance from the headquarters into account, I define whether the police patrol was potentially too far from the crime scene to reach it on time. I use the actual time $\tau_{i, n}$ it takes to travel from the headquarters to the crime scene, and given that Google's estimated durations for Italy do not take traffic into account, I inflate the time $\tau_{i, n}$ by a constant $\kappa \geq 1$ to define the "intention to treat status:" 30

$$
I\left(\left|t_{i, n}-T\right| \leq \kappa \tau_{i, n}\right)
$$

Table 5 presents the estimated $\delta$ s using $\kappa$ from 1 to 1.5 in increments of $1 / 10$, based on Fourier regressions (Columns 1 and 2) and on $\pm 1 h 15 m$ around shift change samples (Columns 3 and 4 ). In line with a more precise treatment status, the results are larger than before. The largest shift change effects are obtained when using $\kappa=1.2$, meaning that for police patrols Google's estimated travel time is 20 percent lower than the actual one, or that patrols tend to anticipate the end or delay the start of their shift.

\footnotetext{
${ }^{29}$ Given that there are 2 areas out of three that are covered by the Polizia the fraction of such areas is approximately equal to 30 percent.

${ }^{30} \mathrm{As}$ a proxy for congestion and relative speed one can look at the number of cars that enter the city center and at the average speed of city buses (which is only available starting at 5am). The Online Appendix Figure 13 shows that there is no congestion at night (average speed of buses is between 14 and $16 \mathrm{~km} / \mathrm{h}$ ), while the peak inflow of cars is between 8 am and $9 \mathrm{am}$, which corresponds to the lowest average speed for public buses $(8 \mathrm{~km} / \mathrm{h})$. At $7 \mathrm{am}, 1 \mathrm{pm}$, and $7 \mathrm{pm}$ the inflow of cars into the city center is close to 5000 cars every half hour, and the average speed of public buses is close to $10 \mathrm{~km} / \mathrm{h}$. The inflow of cars might be a poor proxy of congestion in the afternoon when most cars drive out of the city. In the evening the average speed of public buses starts increasing at $6 \mathrm{pm}$, but overall shift change intervals during daytime are not subject to exceptional congestion.
} 


\section{Testing for Deterrence}

There are several statistics that could signal the presence of deterrence related to shift changes. Deterrence would lead to differences in the distribution, composition, as well as evolution of robberies.

\subsection{Distribution of Robberies and Congestion}

Let us start with the distribution. The distribution of robberies by time of the day shows that the excess mass is driven by robberies that happen when businesses are about to close, around both lunch time and dinner time (see Figure 5 , time goes from 0 to 24). Most business are only open during the day, typically between 8 am and 8 pm, which is when most robberies take place. 31

\subsubsection{Congestion}

Shift changes are close to such spikes, and thus one might worry that the productivity of the police patrols suffer because of congestion. Yet, since there is on average less than one robbery in each shift (exactly 0.375), this channel is unlikely to be an important one ${ }^{32}$ A simple way to test for congestion is to restrict the analysis to the set of first robberies of the day.

If in a given day the police officers are busy investigating the first robbery, for the subsequent ones the productivity may be harmed. This would be particularly troublesome in case of congestion. Table 6 computes the shift change effects focussing on the very first robbery of the day that a given police force has to deal with. If anything, congestion appears to bias the effects towards zero.

\footnotetext{
${ }^{31}$ Figure 6 shows the distribution for major crime categories.

${ }^{32}$ In order to see whether other crimes produce congestion effects during shift changes, I use the average daily number of thefts in 15 minute intervals that happened between 2009 and 2010 in Milan. These tables are based on the official police reports collected by the Central Police Department in Rome (Servizio Analisi Criminale). The daily number of thefts are shown in Figure 6. I reduce the heaping at [0-14] minute and [30-44] minute intervals shown in the Online Appendix Figure 15 distributing a mass proportional to the relative degree of heaping to the [15-29] and [45-59] minute intervals. The assumption is that over the entire day thefts are uniformly distributed over the four 15-minute intervals. While there are on average only 1.5 robberies each day, every 15 minutes there are about 3 thefts. None of the average number of thefts shows a clear spike during shift changes. The numbers are typically higher either before or after the shift changes. Bag-snatching and pick-pocketing crimes tend to be high during the entire day, while burglaries spike in the morning when victims are likely to realize the theft. Other kinds of thefts spike around 8pm. I would like to thank Ernesto Savona from Transcrime, the Joint Research Centre on Transnational Crime, for sharing these data.
} 


\subsubsection{Distribution}

In the absence of congestion, a mass around shift changes might still signal that criminals know about potential police disruptions around shift changes. ${ }^{33}$ And if the more knowledgable robbers were also the more able ones, heterogeneity in knowledge would generate heterogeneity in ability, which might bias the shift change effects downward.

Before running the regressions it is useful to look at the histogram of the the time centered around shift changes. Figure 7 shows the histogram in 15 minute bins of the event time (left panel) and of the absolute value of event time (right panel). Taking the absolute value collapses the potential jump 15 minutes before shift changes (the first vertical line, -0.25) and the potential jump 15 minutes after shift changes (the second vertical line, +0.25$)$ into one potential jump $(+0.25)$. In line with the time of the day histogram (Figure 5) there is evidence of a discontinuity at -0.25 and at +0.25 , but no matter which histogram one looks at, the direction of the jump is opposite of the one that (lack of) deterrence would generate.

That none of these changes appear to be related to an endogenous response of robbers is more readily visible when one exploits the heterogeneity based on distance from the headquarters. Unobserved conditions faced by robbers (i.e. the exact opening time of businesses, the visibility on the street and inside the business premises due to weather conditions, sunlight, etc.) as well as their individual constraints (i.e. their working hours in legitimate jobs, etc.) could be contributing to such drop. Since these conditions and constraints are not changing with the distance from the headquarters and the police disruptions were concentrated far from the headquarters, a difference-in-differences test is a more powerful one.

Figure 8 shows the two histograms conditional on whether the businesses are below or above the median distance from the headquarters. There are no major differences between the two histograms.

Next, in order to generate a single test statistic I mimic the analysis performed for the likelihood of clearing a case, estimating Equation 2 and 3 using the number of robberies as the dependent variable. Whether these differences are significant is shown in Table 7. The table presents Poisson model estimates of shift change effects, where the dependent variable is the number of robberies aggregated by 15 minute periods (there are 96 such periods), by area (north-east, north-west, south), by median distance from the headquarters (HQ), and by shift change day type (from 1 to 3 ). There are a total of 1,656 observations. All estimates can be interpreted as semi-elasticities. While there is some

\footnotetext{
${ }^{33}$ Evidence that thefts and burglaries do not cluster around shift changes is shown in Figure 6 .
} 
evidence that robberies spike around shift changes when compared to control periods (in the event study approach the control period is 1 hour and 15 minutes from the shift change interval), there is no evidence that during shift changes robbers are more likely to target businesses that are located farther away from the headquarters, which is when and where the entire disruption takes place. Columns 3 and 4 show that the number of robberies does not differ depending on whether the Polizia maintains control over the area (smooth changeover).

\subsection{Balance Tests}

While one can rule out that congestion is driving the reduction in police performance during shift changes, or that during such police disruption robbers try to target businesses that are located far from the police headquarters, balance tests can tell us whether those who do select the right time and place appear to be more able criminals. Beyond making a safe escape, the other most important measure of success is the value of the loot.

While the summary statistics table showed that the loot, as well as the other characteristics of robbers and robberies during shift changes differ little with respect to the rest of the day, there might still be discontinuities close to the shift changes. The upper panel of Table 8 performs the test for discontinuities for covariates around the shift change, using the Fourier as well as the $\pm 1 h 15$ min before and after shift change sample. The lower panel shows the difference-in-differences estimate, where the additional difference is based on whether the distance between the victim and the headquarters is above the median.

The simple differences coincide with the differences shown in the summary statistics (Table 1). Even the difference-in-differences show little evidence of ability difference, and they typically go in the opposite direction: robbers are less likely to be armed, and the groups of robbers tend to be smaller.

Arguably the single most important variable to measure ability is the value of the stolen good, and average differences might hide some heterogeneity (Bitler et al., 2006, see). Figure 9 displays the whole cumulative distribution functions depending on the shift change status focussing on robberies that happen close to shift changes $( \pm 1 \mathrm{~h} 15 \mathrm{~m})$. Using a Kolmogorov-Smirnov test one cannot reject that the two distribution functions are the same. 


\subsection{Summary of Additional Tests}

For brevity several additional deterrence tests are in the Appendix Section A.3. In short, there is no evidence that robbers who have the ability to be more unpredictable, because they target businesses that are less clustered in space, are more likely to target shift changes. There is also no evidence of learning about the opportunity given by shift changes: robbers who targeted a shift change are not more likely to target it in later robberies. There is also no evidence that the shift change effects are closer to zero for robbers who for the first time target a shift change, and therefore are less likely to be part of a selected group of more knowledgable and possibly able robbers.

\section{Deterrence vs. Incapacitation}

To understand how changes in clearances translate into differences in crime rates, and what kind of assumptions are needed to establish more general findings, I start with an individual model of crime where criminals can potentially repeatedly commit crimes ${ }^{34}$ At time $t$ an individual decides to commit a crime when his/her expected utility from doing so is positive, $(1-\pi) U-\pi D-u_{t}>0$, where $\pi$ is the perceived "clearance rate" (which may depend on the true clearance rate $c$ and on the level of policing $p: \pi(c(p), p))$. $U$ is the utility from the loot, and $D$ the disutility from spending $S$ years in prison; $u_{t}$ is the opportunity cost from committing a crime at time $t$ (e.g. legal earnings). The likelihood of committing a crime is

$$
F_{t}=F_{t}(U-\pi(D+U))
$$

where $F_{t}$ is the cumulative distribution function of $u_{t}$. With yearly data and no repeat offending within the year $F$ represents the crime rate ${ }^{35}$ But within a year, $u_{t}$ is likely to be fairly persistent for the same individual (for example, due to long term unemployment), and each year there could be multiple crime opportunities. This introduces repeat offending.

In the extreme case of full persistence within the year $F_{t}=F$, and if there is a large number of criminal opportunities, the crime rate is not just $F$, but

$$
C(c)=\sum_{t} F(1-c)^{t} \approx \frac{F}{c} .
$$

\footnotetext{
${ }^{34}$ With the exception of repeat offenses the setup is similar to the one used by Durlauf et al. (2010)).

${ }^{35}$ When aggregate crime regressions are linear in clearance rates $c$, researchers are implicitly assuming that the errors (the outside opportunities) are uniformly distributed.
} 
Potential criminals start offending with probability $F$ and move to a second crime if not arrested, which happens with probability $1-c$. The probability of committing a third offense is $(1-c)^{2}$ etc. The implied assumption for this formula is that in case of arrest the incapacitation lasts longer than a year. Both assumptions are reasonable when dealing with robbers. Their sentences tend to be between 3 and 4 years and there is strong evidence of repeat offending within the year 36

The incapacitation effect $1 / c$ in Equation 5 gives rise to a strong convex relationship between crime rates and clearance rates 3738

Figure 10 plots 20 years of yearly province level aggregate crime rates for robberies and for motor vehicle thefts against the corresponding clearance rates (defined as the number of cleared crimes over the total number of crimes in a year). The relationship is strongly convex, and the simple re-scaled prediction based on the incapacitation effect $1 / c$ fits the data quite well. 39

In order to evaluate the relative strength of incapacitation and deterrence I can express the elasticity of crime with respect to police $\varepsilon_{C, p}$ as the product between the elasticity of crime with respect to clearance rates $\varepsilon_{C, c}$ (which potentially contains both, an incapacitation and deterrence effect) and the elasticity of clearance rates with respect to police $\varepsilon_{c, p}$.

$$
\frac{\partial C}{\partial p} \frac{p}{C}=\frac{\partial C}{\partial c} \frac{c}{C} \times \frac{\partial c}{\partial p} \frac{p}{c}
$$

In the absence of deterrence, or if $F$ does not depend on $c$, from Equation $5 \varepsilon_{C, c}=-1$ and $\varepsilon_{C, p}=-\varepsilon_{c, p}$, meaning that the effect of police on crime is completely driven by how additional police resources translate into increased clearance rates.

Without information on the exact number of active police patrols I cannot measure the reduction in policing during shift changes, but according to the Police Union the average

\footnotetext{
${ }^{36}$ The upper quartile time difference between crimes organized by the same robbers is two weeks, meaning that by extrapolation 75 percent of robbers would organize more than 26 robberies in a year.

${ }^{37}$ Several functional forms have been used in the literature to model crime as a function of clearance rates. Levitt (1998) and Glaeser and Sacerdote (1999) use a log-log specification, Machin and Meghir (2004) use a probability odds-log specification, and Mustard (2003) uses a log-level specification.

${ }^{38}$ For the deterrence effect driven by $F$, convexity or concavity depend on how $\pi$ depends on police presence and on the shape of the density of $u$ around the marginal criminal.

${ }^{39} \mathrm{On}$ a related note, trying to measure incapacitation using the relationship between arrests and policing would be a mistake. As Levitt and Miles (2004) and Owens (2011) point out, the theoretical predictions about arrest rates are ambiguous. More policing can potentially reduce the arrests in case of deterrence as well as increase them in case of incapacitation. Since Evans and Owens (2007) show that the COPS program reduced overall crime, while Owens (2011) finds no effect of such a program on arrests, there is arguably indirect evidence that deterrence and incapacitation are both present.
} 
number of working cars is 25 , while cars on patrol range between 15 and 20.40 This means that between $1 / 3$ to $2 / 3$ of patrolling cars need to perform the shift change inside the headquarters. Taking the conservative estimate of a $2 / 3$ reduction in police presence we need to divide our intention to treat effect of -0.05 by $2 / 3$ to get an average treatment effect $\left(\frac{\partial c}{\partial p}\right)$ of -0.075 . Dividing this number by the average clearance rate (15 percent) we get that the elasticity $\varepsilon_{c, p}$ is equal to 0.5 . To assess the importance of incapacitation we now need an estimate of $\varepsilon_{C, p}$.

The elasticity estimate for Italian robberies in Buonanno and Mastrobuoni (2011) is $\frac{\partial C}{\partial p} \frac{p}{C}=-0.56$, and is in line with Chalfin and McCrary (2018)'s preferred estimate. Other elasticity estimates are more negative (-1.34 in Evans and Owens (2007), -1.86 in Lin (2009) and -1.20 in Levitt (1997)).

While any reduction in total elasticity, driven for example by measurement error bias in police numbers, would lower the importance of incapacitation over deterrence, a total elasticity of -0.56 implies that incapacitation is the main driver for robbery reductions when police numbers increase.

\section{Conclusions}

Using precise micro-level information about robberies against businesses, coupled with some peculiar rules about shift changes, this paper shows that disrupting police patrolling reduces the likelihood of clearing a robbery (i.e. arresting at least one of the perpetrators). Since most of the robbers are professional criminals who tend to re-offend on a weekly basis (see Mastrobuoni, 2016), the disruptions generate sizeable negative incapacitation effects.

A battery of different tests for selection and deterrence suggests that most robbers are completely unaware of these disruptions. This might be partly due to the fact that, except for the time when there is a shortage of police cars and such cars are physically inside the police headquarters, police cars remain visible.

What can be learned from such a specific "low-visibility" quasi-experimental change in policing? If criminals are aware of typical, business as usual, policing levels, the ultimate effect on crime of such policing would most likely be a combination of deterrence and incapacitation. In much the same way, following a terrorist attack, continuously guarding specific areas is likely to produce an upper bound of deterrence and a lower bound of

\footnotetext{
${ }^{40}$ The Polizia keeps records about the outgoing and incoming police cars for two weeks before destroying such information, but would not disclose such information. The Carabinieri do not disclose their numbers, but if they are proportional to the number of Polizia cars they should have around 10 cars.
} 
incapacitation compared to a "typical" police officer-who is neither constantly guarding a building, ${ }^{41}$ nor constantly driving around the city-the Milan shift-changes are likely to produce opposite bounds. The "typical' police officer is likely to be less predictable than a stationing officer, and more predictable than one that is rotating during shift changes.

In terms of policy implications, this paper highlights an issue related to shift changes. During these changes businesses located far away from the headquarters need more patrolling. To eliminate the shift change effects the Italian law prescribes shift changes out on the street, which requires twice the active number of police cars. A less costly and more realistic strategy to reduce disruption would be to have overlapping shift changes. 42 Another strategy would be to set the shift changes at times when the lowest number of crimes are committed (the Online Appendix Section A.2 computes an optimal shift change regime).

To better understand whether Milan's patrolling levels are suboptimal, as well whether disregarding the shift change rule is generating welfare losses, I start by imputing the cost of additional police cars. The per unit price tag on the last batch of SEAT Leon police cars was $€ 43,897$, about $\$ 50,000$. Assuming that the car drives $100,000 \mathrm{~km}$ per year (this would mean that the car runs for about 12 hours each single day and drives at an average speed of $25 \mathrm{kph}(15 \mathrm{mph})$ when in service) and becomes obsolete after 10 years, with a yearly cost of insurance $(€ 2,000)$, depreciation $(€ 4,500)$, gas $(€ 4,000)$ and repairs $(€ 3000)$, the cost of the car would be about $€ 13,500$ per year.

With two additional drivers that are paid average police wages, the total cost would increase to about $€ 50,000$. A 20 percent increase in police patrols, from 30 to 36, would thus cost about $€ 300,000$ per year. Regarding shift changes, if these cars were sitting in the garage in need of repairs, the depreciation cost would have to be excluded, and so would be the cost for the drivers. The yearly additional cost would be only $€ 56,000$.

Based on the estimated elasticities, a 20 percent increase in patrols leads to a 10 percent increase in clearance rates, from 15 to 16.5 percent. This would reduce the expected number of robberies committed by each repeat offender before an arrest takes place by 0.6 . Given that every year about 85 new repeat offenders start robbing businesses, an average of 51 robberies are prevented.

Additional arrests may also increase judicial spending. With respect to repeat offenders, this study suggests that most prolific offenders will eventually end up in prison. In other words, with decently sized clearance rates $(1-c)^{t}$ converges to 0 reasonably

\footnotetext{
${ }^{41}$ As in Di Tella and Schargrodsky (2004), Klick and Tabarrok (2005) and Draca et al. (2011).

${ }^{42}$ For example, half of the Pittsburgh Police units change at a specific time, the other half one hour later.
} 
quickly, and improved clearance rates only anticipate the time of arrest, with little effect on spending. As for the cost of arresting the marginal "one time" offender, while such cost is harder to pin down, it also tends to be smaller because of sentence suspensions, probation, etc. that many countries, including Italy, have in place for first time offenders.

Evaluated at the average haul the 51 fewer robberies reduce social losses by about $€ 143,000.43$ For shift changes this already outweighs the cost, which implies that the Italian police forces should invest in maintaining a sufficient number of working police cars to avoid disruptive shift changes.

It does not cover the full cost of 6 additional patrols, but indirect losses (Cook, 2009) and reduced losses for other types of crime are likely to overturn this result. ${ }^{44}$

\section{References}

Donald W.K. Andrews. Asymptotic normality of series estimators for nonparametric and semiparametric regression models. Econometrica, (2):307-345, 1991.

Gary S. Becker. Crime and punishment: An economic approach. The Journal of Political Economy, 76(2):169-217, 1968.

Sara Biondini. Schiaffo di Pisapia "Militari Inutili, ronde negative". Libero, November 8 2011.

Marianne P. Bitler, Jonah B. Gelbach, and Hilary W. Hoynes. What Mean Impacts Miss: Distributional Effects of Welfare Reform Experiments. American Economic Review, 96 (4):988-1012, September 2006.

Jordi Blanes i Vidal and Tom Kirchmaier. The effect of police response time on crime clearance rates. The Review of Economic Studies, 85(2):855-891, 2017.

Paolo Buonanno and Giovanni Mastrobuoni. Police and crime: Evidence from dictated delays in centralized police hiring. Technical report, 2011. mimeo.

R.A. Carr-Hill and N.H. Stern. An econometric model of the supply and control of recorded offences in england and wales. Journal of Public Economics, 2(4):289 - 318, 1973.

\footnotetext{
${ }^{43}$ This disregards the welfare of criminals, and so losses are not treated as simple transfers.

${ }^{44}$ In 2009 the city of Milan had a total of about 149,000 crimes. For total crime the elasticity with respect to police patrols is -0.25 (see Buonanno and Mastrobuoni 2011), meaning that a 20 percent increase in patrols will translate into 7,450 fewer crimes. The break-even cost per crime would be just $€ 21$.
} 
Michael L Carriaga and John L Worrall. Police levels and crime: A systematic review and meta-analysis. The Police Journal, 2015.

Aaron Chalfin and Justin McCrary. Are US cities underpoliced? Theory and evidence. Review of Economics and Statistics, 100(1):167-186, 2018.

Philip Cook, Jens Ludwig, and Justin McCrary. Economical crime control. In Controlling Crime: Strategies and Tradeoffs, NBER Books, pages 331-363. National Bureau of Economic Research, Inc, 2011.

Philip J Cook. The clearance rate as a measure of criminal justice system effectiveness. Journal of Public Economics, 11(1):135-142, 1979.

Phillip Cook. Robbery. In Michael Tonry, editor, Oxford Handbook on Crime and Public Policy. Oxford University Press, 2009.

Gary W. Cordner. Police agency size and investigative effectiveness. Journal of Criminal Justice, 17(3):145 - 155, 1989.

Hope Corman and H. Naci Mocan. A time-series analysis of crime, deterrence, and drug abuse in new york city. American Economic Review, 90(3):584-604, June 2000.

Steven G. Craig. The deterrent impact of police: An examination of a locally provided public service. Journal of Urban Economics, 21(3):298 - 311, 1987.

R. Di Tella and E. Schargrodsky. Do police reduce crime? Estimates using the allocation of police forces after a terrorist attack. The American Economic Review, 94(1):115-133, 2004.

Mirko Draca, Stephen Machin, and Robert Witt. Panic on the Streets of London: Police, Crime and the July 2005 Terror Attacks. American Economic Review, 101(5):2157-81, 2011.

Steven N Durlauf and Daniel S Nagin. Imprisonment and crime. Criminology \&s Public Policy, 10(1):13-54, 2011.

Steven N. Durlauf, Salvador Navarro, and David A. Rivers. Understanding aggregate crime regressions. Journal of Econometrics, 158(2):306 - 317, 2010.

Editorial Office. Cento volanti ferme in questura. E non ci sono soldi per aggiustarle. Il Giornale, November 82011. 
Isaac Ehrlich. Participation in illegitimate activities: A theoretical and empirical investigation. Journal of Political Economy, 81(3):521-65, 1973.

William N. Evans and Emily G. Owens. COPS and Crime. Journal of Public Economics, 91(1-2):181-201, 2007.

Luis Garicano and Paul Heaton. Information technology, organization, and productivity in the public sector: evidence from police departments. Journal of Labor Economics, 28(1):167-201, 2010.

Pier Paolo Garofalo. Macchine vetuste e mal equipaggiate, ma la polizia funziona. Il Piccolo, November 2013.

Edward L. Glaeser and Bruce Sacerdote. Why is there more crime in cities? Journal of Political Economy, 107(S6):pp. S225-S258, 1999.

Jonathan Klick and Alexander Tabarrok. Using terror alert levels to estimate the effect of police on crime. Journal of Law \& Economics, 48(1):267-79, April 2005.

Tracey Kyckelhahn. Justice expenditures and employment, fy 1982-2007-statistical tables. Bureau of Justice Statistics. Washington, DC: US Department of Justice, 2011.

Steven D Levitt. Using electoral cycles in police hiring to estimate the effect of police on crime. American Economic Review, 87(3):270-90, June 1997.

Steven D Levitt. Why do increased arrest rates appear to reduce crime: deterrence, incapacitation, or measurement error? Economic inquiry, 36(3):353-372, 1998.

Steven D. Levitt and T. Miles. Empirical Study of Criminal Punishment. The Handbook of Law and Economics, 2004.

Ming-Jen Lin. More police, less crime: Evidence from us state data. International Review of Law and Economics, 29(2):73-80, 2009.

Stephen Machin and Olivier Marie. Crime and police resources: The street crime initiative. Journal of the European Economic Association, 9(4):678-701, 2011. ISSN 1542-4774.

Stephen Machin and Costas Meghir. Crime and economic incentives. Journal of Human Resources, 39(4), 2004.

Alexandre Mas. Pay, reference points, and police performance. The Quarterly Journal of Economics, 71(3):783-821, 2006. 
Giovanni Mastrobuoni. Optimal criminal behavior and the disutility of jail: Theory and evidence on bank robberies. Carlo Alberto Notebooks 220, Collegio Carlo Alberto, 2011.

Giovanni Mastrobuoni. Crime is terribly revealing: Information technology and police productivity. mimeo, 2016.

Vijay K. Mathur. Economics of crime: An investigation of the deterrent hypothesis for urban areas. The Review of Economics and Statistics, 60(3):pp. 459-466, 1978.

David B. Mustard. Reexamining criminal behavior: The importance of omitted variable bias. The Review of Economics and Statistics, 85(1):205-211, February 2003.

Whitney K. Newey, James L. Powell, and James R. Walker. Semiparametric estimation of selection models: Some empirical results. The American Economic Review, 80(2): 324-328, 1990.

Emily Owens. Cops and cuffs. mimeo, 2011.

Brian A Reaves. Local police departments (2007). U.S. Department of Justice, Office of Justice Programs, Bureau of Justice Statistics, 2011.

Lawrence W. Sherman. Policing for crime prevention. In Evidence-based crime prevention, page 295. A Report to the United States Congress, prepared for the National Institute of Justice, 2002.

Lawrence W Sherman. The rise of evidence-based policing: Targeting, testing, and tracking. Crime and Justice, 42(1):377-451, 2013.

Lawrence W Sherman and David Weisburd. General deterrent effects of police patrol in crime "hot spots": A randomized, controlled trial. Justice Quarterly, 12(4):625-648, 1995.

Wesley Skogan and Kathleen Frydl. Fairness and Effectiveness in Policing: the Evidence. Committee on Law and Justice, Division of Behavioral and Social Sciences and Education. Washington DC: National Academies Press, 2004.

Wesley Skogan, Kathleen Frydl, et al. Fairness and effectiveness in policing: The evidence. National Academies Press, 2004. 
Richard Thaler. An econometric analysis of property crime. Journal of Public Economics, 8:37-51, 1977.

David Weisburd and John E Eck. What can police do to reduce crime, disorder, and fear? The Annals of the American Academy of Political and Social Science, 593(1): 42-65, 2004.

Kenneth I. Wolpin. An economic analysis of crime and punishment in england and wales, 1894-1967. Journal of Political Economy, 86(5):pp. 815-840, 1978. ISSN 00223808. 


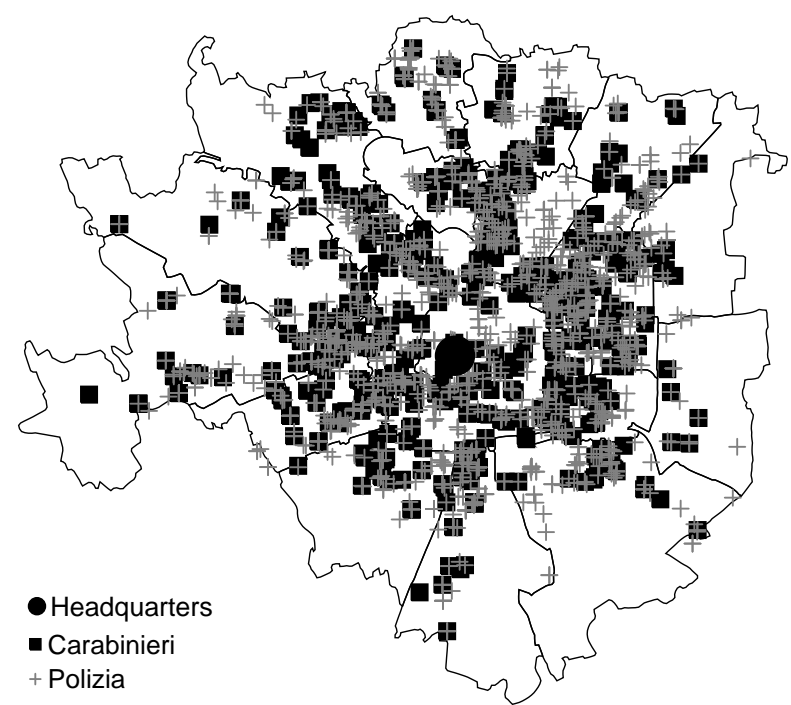

Figure 1: Headquarters' location

Notes: The black dot indicates where the Polizia and the Carabinieri headquarters are located. The squares and crosses indicate the location of robberies assigned to the two forces. 

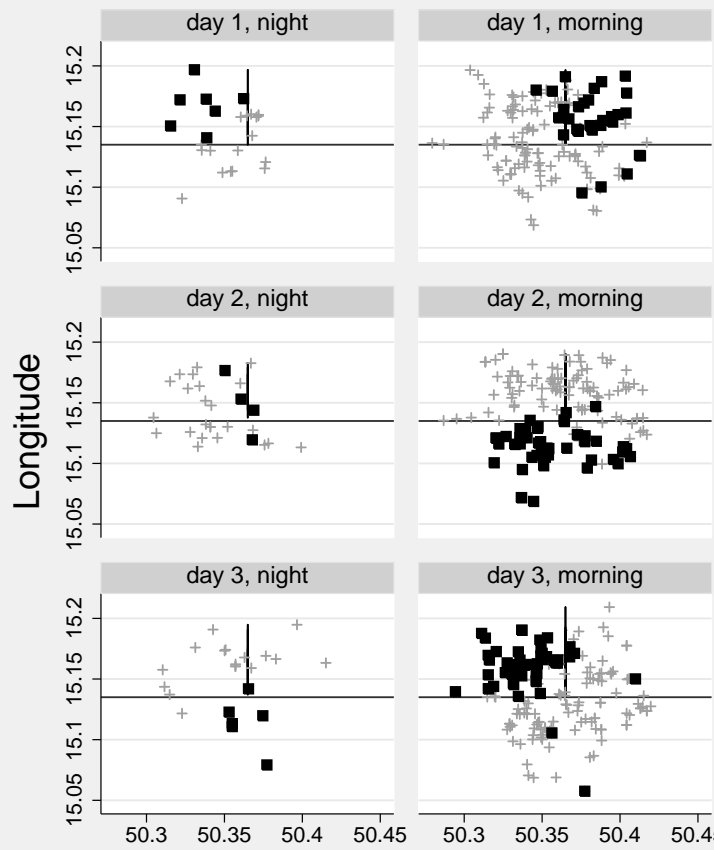

day 2 , morning

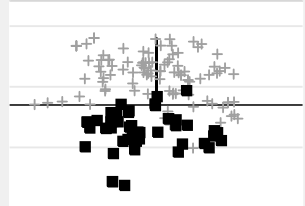

day 3 , morning
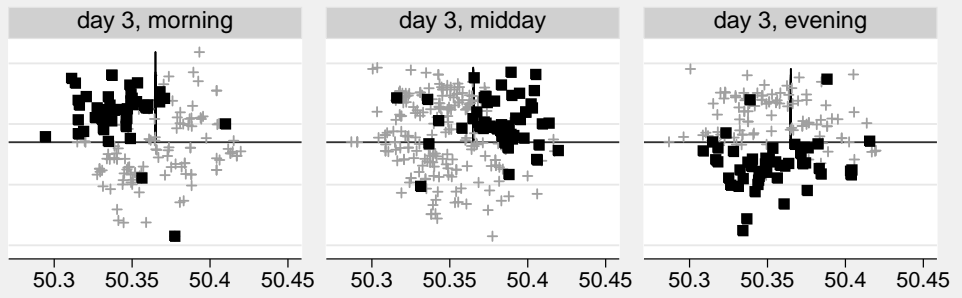

+ Police

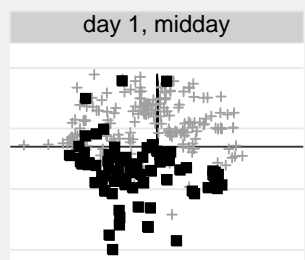

day 2 , midday

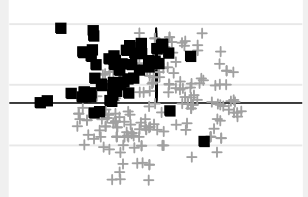

day 3 , midday

\section{Gendarmerie}

Figure 2: Geographic Distribution of Robberies by Group

Notes: Groups are defined based on the exact day and time of a robbery. Coordinates use Gauss-Boaga projections.

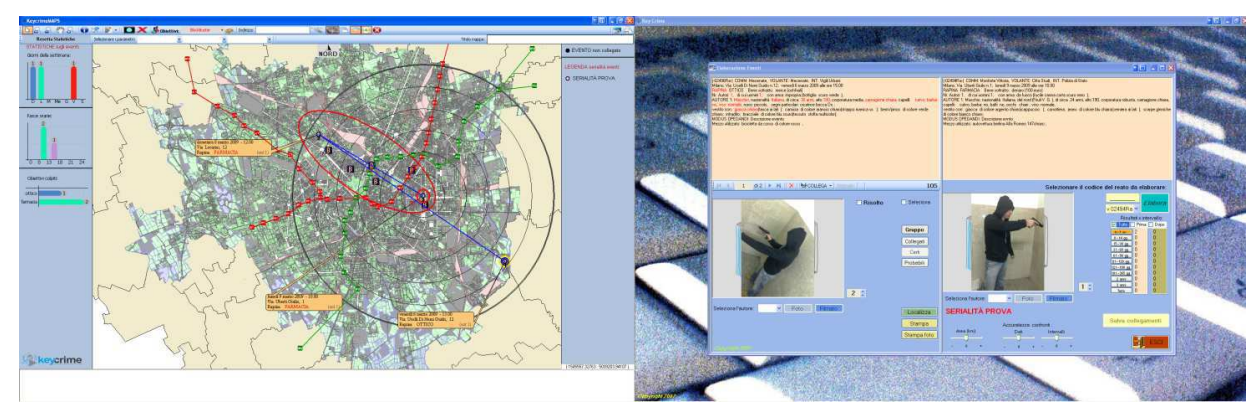

Figure 3: Comparison of Events 

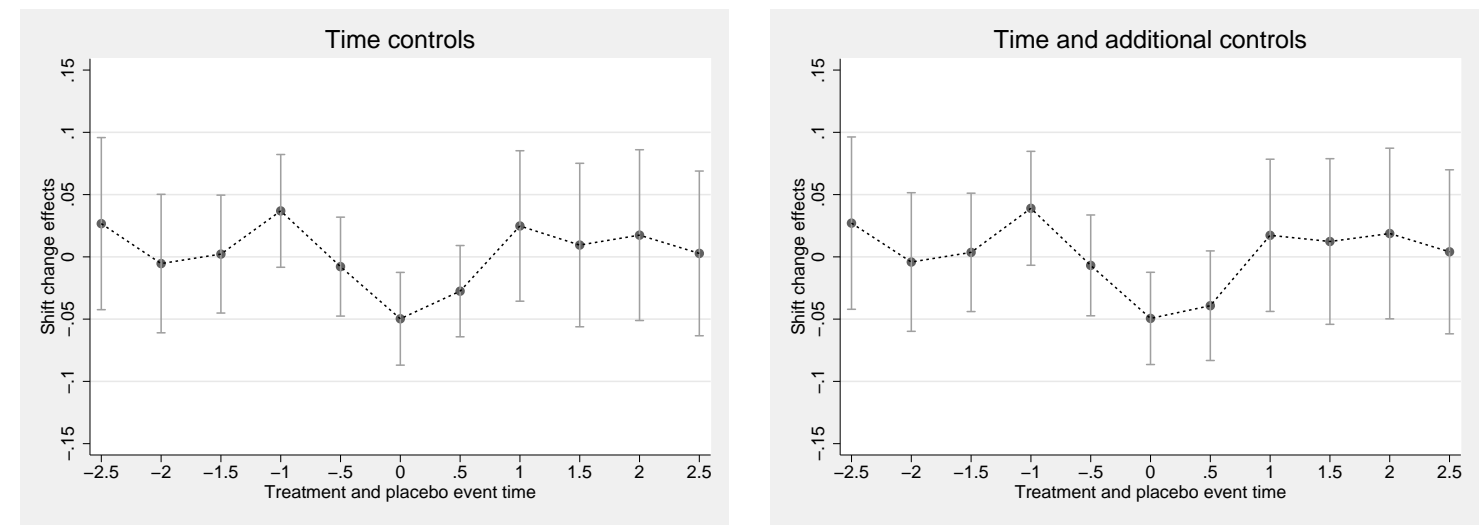

Figure 4: Shift Change Treatment and Placebo Effects on Clearance Rates

Notes: Each dot represents a different coefficient, and the corresponding vertical lines the 95 percent confidence intervals (based on clustered, by series, standard errors). Event time measures the time (in hours) from shift changes ranging from -2.5 hours to +2.5 hours. The estimate corresponding to the event time 0 corresponds to the correct shift change (centered at $12 \mathrm{am}, 7 \mathrm{am}, 1 \mathrm{pm}, 7 \mathrm{pm}$ ). There is one estimate for each placebo (event time $\neq 0$ ) shift change shifted by 30 minutes forward or backward. All estimates control for a cubic Fourier series, while the right panel controls for the shops' closing time dummies. 


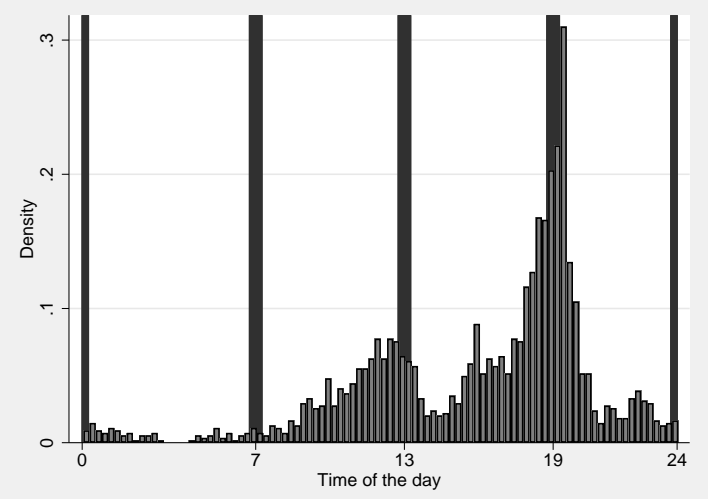

Figure 5: Distribution of Robberies

Notes: The histogram uses 15 minute bins. The darker vertical intervals indicate the half-hour shift change periods around shifts.
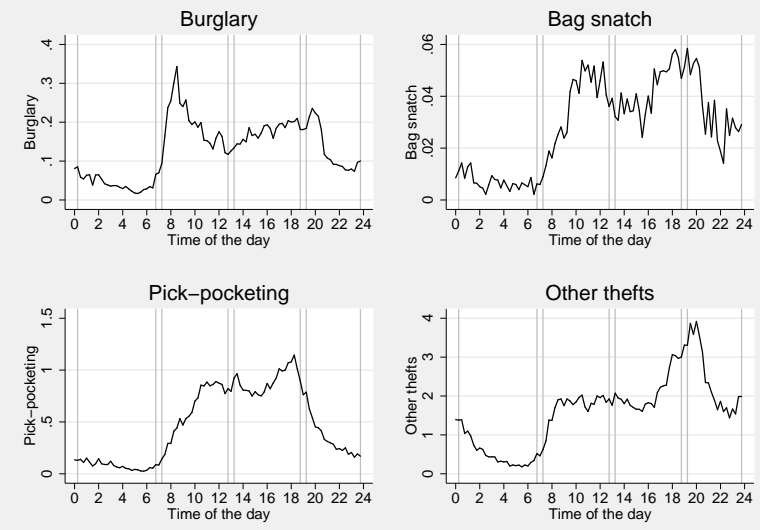

Figure 6: Average Number of Daily Thefts in 15 Minute Intervals

Notes: Based on 93 percent of all thefts that occurred in in Milan between 2009 and 2010. The series has been smoothed to reduce heaping. Data about reported thefts have been provided to Transcrime (Joint Research Centre on Transnational Crime) by the Servizio Analisi Criminale (Crime Analysis Department) of the Italian Ministry of the Interior within the framework of the project "Crime in Metropolitan Areas." Vertical lines indicate the half-hour shift change periods around shifts. 

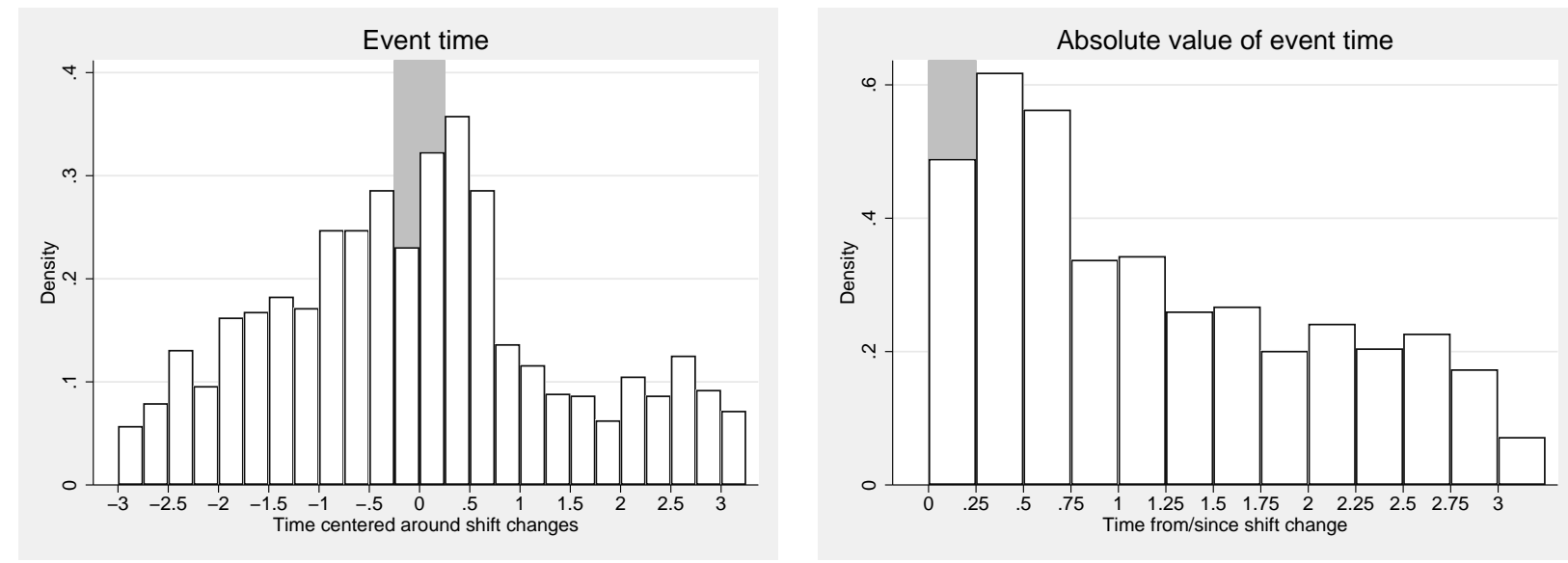

Figure 7: Distribution of Event Time and Absolute Value of Event Time

Notes: Event time measures the time (in hours) from shift changes ranging from -3 hours to +3 hours. The absolute value of event time is shown in the right panel. Histograms use 15 minute bins. The darker vertical interval indicates the half-hour shift change periods around shifts. 


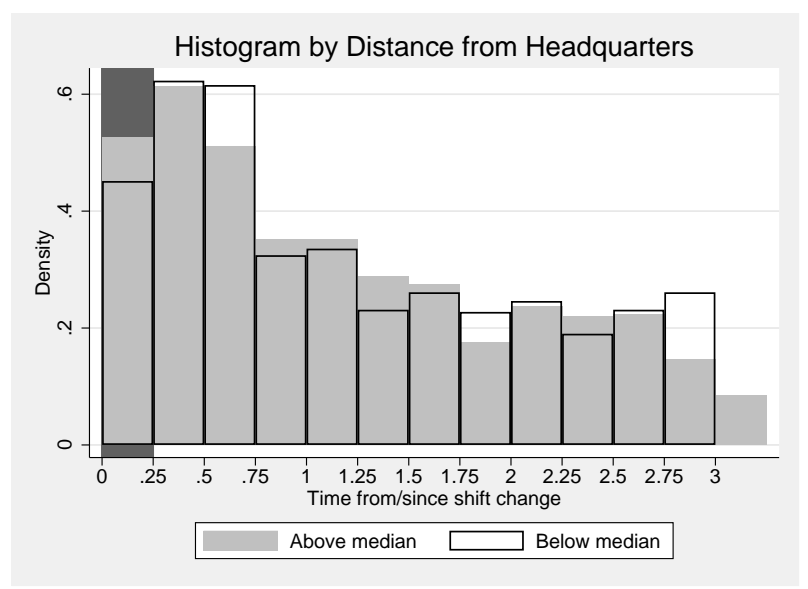

Figure 8: Absolute Value Event Time Histograms by Distance from Headquarters and by Smoothness of the Shift Change

Notes: Histograms use 15 minute bins. The darker vertical intervals indicate the half-hour shift change periods. 


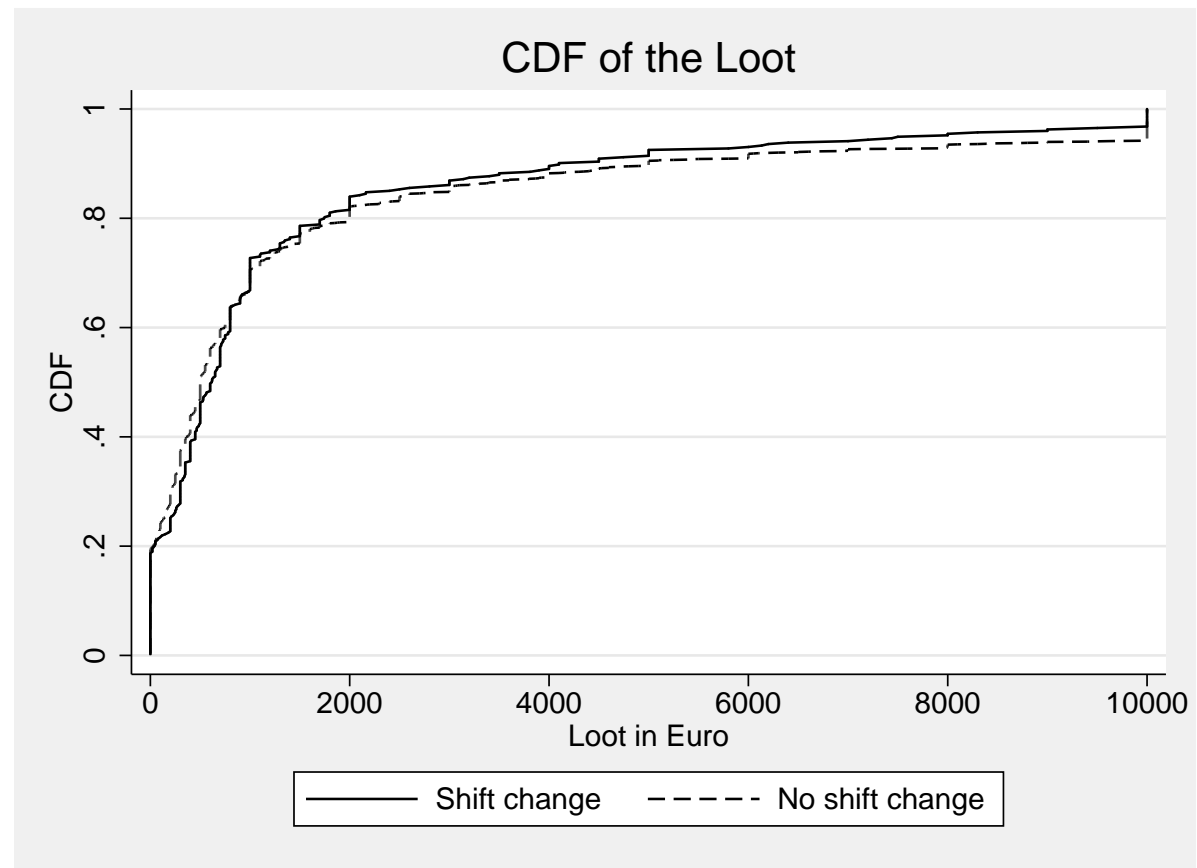

Figure 9: Cumulative Distribution of the Loot

Notes: The sample is based on robberies that happen within 1 hour and 15 minutes from the shift changes. The loot has been truncated at $€ 10,000$. The p-value of the two-sample Kolmogorov-Smirnov test for equality of distribution functions without truncation is 16.7 percent.

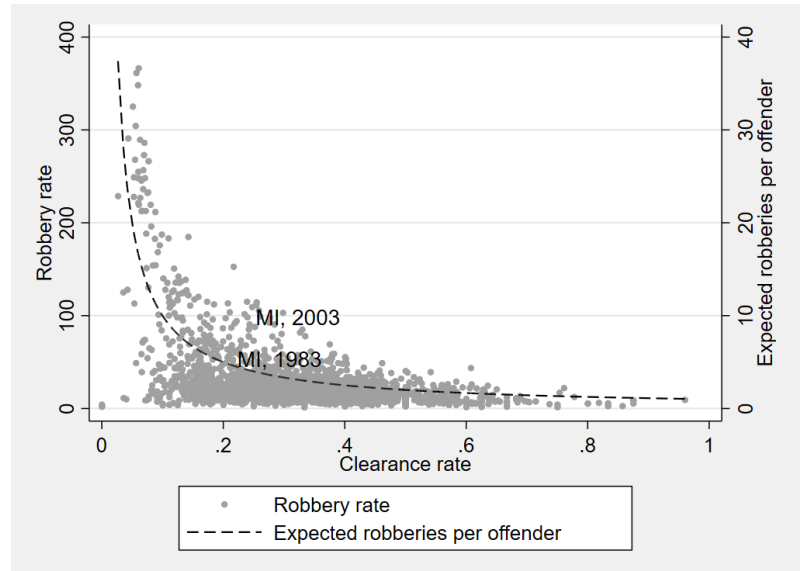

Figure 10: Aggregate Robbery Rates and Clearance Rates

Notes: The dashed line simply plots the inverse of the clearance rate. Based on 103 Italian provinces between 1983 and 2003. 
Table 1: Summary statistics

\begin{tabular}{|c|c|c|c|c|c|c|}
\hline \multirow[t]{3}{*}{ Variable } & \multicolumn{4}{|c|}{ Shift change } & \multicolumn{2}{|c|}{ Difference } \\
\hline & \multicolumn{2}{|c|}{ Yes } & \multicolumn{2}{|c|}{ No } & & \\
\hline & Mean & Std.Dev. & Mean & Std.Dev. & Mean & Std.Err. \\
\hline \multicolumn{7}{|l|}{ Characteristics of the investigators } \\
\hline Cleared robbery & 0.091 & 0.288 & 0.148 & 0.355 & -0.057 & $0.019^{* * *}$ \\
\hline Polizia (Police) $0 / 1$ & 0.745 & 0.436 & 0.730 & 0.444 & 0.015 & 0.026 \\
\hline Predictive policing (Keycrime) & 0.249 & 0.433 & 0.234 & 0.424 & 0.015 & 0.027 \\
\hline Distance from the headquarters (in minutes) & 14.762 & 4.095 & 14.246 & 4.457 & 0.516 & 0.276 \\
\hline Distance from the headquarters (in kilometers) & 6.024 & 2.134 & 5.756 & 2.275 & 0.268 & 0.148 \\
\hline \multicolumn{7}{|l|}{ Characteristics of the robberies } \\
\hline Amount stolen in euros & 2814.365 & 12335.651 & 2862.969 & 10950.471 & -48.604 & 966.598 \\
\hline Shops' closing time $0 / 1$ (90th percentile) & 0.102 & 0.303 & 0.178 & 0.383 & -0.076 & $0.020 * * *$ \\
\hline Shops' closing time 0/1 (maximum) & 0.048 & 0.214 & 0.088 & 0.283 & -0.039 & $0.015^{* * *}$ \\
\hline Southern area & 0.428 & 0.495 & 0.436 & 0.496 & -0.008 & 0.030 \\
\hline North-Western area & 0.334 & 0.472 & 0.350 & 0.477 & -0.015 & 0.029 \\
\hline Year & 2009.246 & 1.030 & 2009.239 & 1.021 & 0.008 & 0.064 \\
\hline Month & 6.074 & 3.800 & 5.838 & 3.698 & 0.236 & 0.235 \\
\hline Day of the week & 3.278 & 1.921 & 3.228 & 1.809 & 0.050 & 0.112 \\
\hline \multicolumn{7}{|l|}{ Characteristics of the robbers } \\
\hline Serial robbers & 0.629 & 0.484 & 0.574 & 0.495 & 0.055 & 0.031 \\
\hline Number of the series & 6.048 & 8.106 & 4.916 & 6.605 & 1.133 & 0.498 \\
\hline Average age & 26.616 & 11.777 & 26.558 & 12.599 & 0.058 & 0.720 \\
\hline Ages are unknown & 0.085 & 0.279 & 0.104 & 0.306 & -0.019 & 0.018 \\
\hline Firearm $0 / 1$ & 0.258 & 0.438 & 0.224 & 0.417 & 0.033 & 0.030 \\
\hline At least one knife, but no firearm & 0.110 & 0.314 & 0.089 & 0.285 & 0.021 & 0.019 \\
\hline Number of robbers & 1.592 & 0.647 & 1.567 & 0.729 & 0.025 & 0.042 \\
\hline Some Italian & 0.799 & 0.401 & 0.786 & 0.410 & 0.013 & 0.026 \\
\hline N. obs. & \multicolumn{2}{|c|}{353} & \multicolumn{2}{|c|}{1,814} & & \\
\hline
\end{tabular}


Table 2: Event Time Study of Clearance Rates

\begin{tabular}{lccc}
\hline & $(1)$ & $(2)$ & $(3)$ \\
& \multicolumn{2}{c}{ Cleared Robbery } & $(0 / 1)$ \\
30 min. shift change interval (SCI) & $-0.045^{* *}$ & $-0.050^{* *}$ & $-0.044^{* *}$ \\
30 min. SCI shifted by $+1.5 \mathrm{~h}$ & $(0.021)$ & $(0.021)$ & $(0.021)$ \\
& 0.013 & 0.007 & 0.004 \\
30 min. SCI shifted by $-1.5 \mathrm{~h}$ & $(0.038)$ & $(0.038)$ & $(0.037)$ \\
& 0.032 & 0.027 & -0.022 \\
30 min. SCI shifted by $+2 \mathrm{~h}$ & $(0.040)$ & $(0.040)$ & $(0.042)$ \\
& $0.051^{*}$ & 0.048 & 0.009 \\
30 min. SCI shifted by $-2 \mathrm{~h}$ & $(0.030)$ & $(0.030)$ & $(0.033)$ \\
& -0.004 & -0.011 & -0.021 \\
30 min. SCI shifted by $+2.5 \mathrm{~h}$ & $(0.028)$ & $(0.029)$ & $(0.030)$ \\
& 0.014 & 0.007 & -0.009 \\
30 min. SCI shifted by $-2.5 \mathrm{~h}$ & $(0.033)$ & $(0.033)$ & $(0.034)$ \\
& 0.043 & 0.037 & 0.009 \\
Shops' closing time $0 / 1$ (90th percentile) & $(0.034)$ & $(0.035)$ & $(0.035)$ \\
& & -0.029 & -0.028 \\
Shops' closing time $0 / 1$ maximum) & & $(0.021)$ & $(0.023)$ \\
Other Xs & & 0.011 & 0.026 \\
Constant & & $(0.029)$ & $(0.030)$ \\
Observations & No & No & Yes \\
R-squared & $0.136^{* * *}$ & $0.143^{* * *}$ & $0.311^{* * *}$ \\
& $(0.011)$ & $(0.013)$ & $(0.072)$ \\
& 2167 & 2167 & 2167 \\
& 0.006 & 0.007 & 0.062 \\
\hline
\end{tabular}

Notes: Linear probability model of clearing the case with clustered (by series) standard errors in parentheses: ${ }^{* * *} \mathrm{p}<0.01,{ }^{* *} \mathrm{p}<0.05,{ }^{*} \mathrm{p}<0.1$. The SCI dummy variable is equal to one if the robbery happened in the following time intervals: $6.45 \mathrm{am}-7.15 \mathrm{am}, 12.45 \mathrm{pm}-1.15 \mathrm{pm}, 6.45 \mathrm{pm}-7.15 \mathrm{pm}$,

$11.45 \mathrm{pm}-12.15 \mathrm{am}$. The excluded time period is the $1 \mathrm{~h} 15 \mathrm{~min}$ period preceding and 1h15min following the SCI. The other Xs are the value of the stolen loot, a police dummy, a dummy for robbers with some experience, the predictive policing dummy, a south and a north-west dummy, year by month dummies, day of the week dummies, age, age squared, a dummy when age is missing, a firearm dummy, a knife dummy, the number of perpetrators, and whether some of the robbers appeared to be Italian. 
Table 3: Clearance Rate Regressions Controlling for Semi-parametric Functions of Time

\begin{tabular}{|c|c|c|c|c|c|c|}
\hline \multirow{4}{*}{ Shift change 0/1 } & \multirow[t]{2}{*}{$(1)$} & \multirow[t]{2}{*}{$(2)$} & \multirow{2}{*}{\multicolumn{2}{|c|}{$\begin{array}{c}(3) \\
\text { Cleared Robbery }(0 / 1)\end{array}$}} & \multirow[t]{2}{*}{$(5)$} & \multirow[t]{2}{*}{ (6) } \\
\hline & & & & & & \\
\hline & \multicolumn{2}{|c|}{ Fourier series } & \multicolumn{2}{|c|}{ Quartic in time } & \multicolumn{2}{|c|}{ Cubic spline } \\
\hline & $\begin{array}{c}-0.050^{* * *} \\
(0.019)\end{array}$ & $\begin{array}{c}-0.049^{* * *} \\
(0.019)\end{array}$ & $\begin{array}{c}-0.051^{* * *} \\
(0.019)\end{array}$ & $\begin{array}{c}-0.052^{* * *} \\
(0.019)\end{array}$ & $\begin{array}{c}-0.043^{* *} \\
(0.019)\end{array}$ & $\begin{array}{r}-0.041^{* *} \\
(0.019)\end{array}$ \\
\hline Constant & $\begin{array}{c}0.158^{* * *} \\
(0.013)\end{array}$ & $\begin{array}{c}0.158^{* * *} \\
(0.013)\end{array}$ & $\begin{array}{l}0.156^{*} \\
(0.080)\end{array}$ & $\begin{array}{l}0.154^{*} \\
(0.080)\end{array}$ & $\begin{array}{l}0.158^{*} \\
(0.085)\end{array}$ & $\begin{array}{l}0.158^{*} \\
(0.085)\end{array}$ \\
\hline Shops closing FE & No & Yes & No & Yes & No & Yes \\
\hline Observations & 2167 & 2167 & 2167 & 2167 & 2167 & 2167 \\
\hline R-squared & 0.010 & 0.010 & 0.008 & 0.008 & 0.011 & 0.011 \\
\hline
\end{tabular}

Notes: Linear probability model of clearing the case with clustered (by series) standard errors in parentheses: $* * * \mathrm{p}<0.01,{ }^{* *} \mathrm{p}<0.05,{ }^{*} \mathrm{p}<0.1$. The Fourier series contains 2 sine and 2 cosine terms (the optimal size based on cross-validation) and the cubic splines is based on 7 equally distanced knots. Online Figure 12 shows the unconditional smoothed function $f(t)$.

Table 4: Difference-in-Differences: Heterogeneity by Distance from the HQs and Shift Change Type

(1) (2) (3)

\begin{tabular}{cc}
\multicolumn{3}{c}{ Cleared Rob } \\
\hline$-0.077^{* * *}$ & $-0.073^{* *}$ \\
$(0.028)$ & $(0.032)$ \\
-0.002 & -0.009 \\
$(0.027)$ & $(0.029)$ \\
$-0.035^{* *}$ & -0.024 \\
$(0.016)$ & $(0.023)$
\end{tabular}

Shift change in non-retained area

$-0.039 * \quad-0.038$

$(0.022) \quad(0.025)$

$-0.050-0.062$

(0.040) (0.043)

$0.012 \quad 0.028$

Retained area

$\left(\begin{array}{ll}0.020) & (0.027)\end{array}\right.$
Other Xs

Fourier series

30' Event time dummies

Observations

p-value for the difference between the shift change effects

R-squared

$\begin{array}{cccc}\text { Yes } & \text { Yes } & \text { Yes } & \text { Yes } \\ \text { Yes } & \text { No } & \text { Yes } & \text { No } \\ \text { No } & \text { Yes } & \text { No } & \text { Yes } \\ 2167 & 2167 & 2167 & 2167 \\ 0.0532 & 0.137 & 0.819 & 0.633 \\ 0.067 & 0.066 & 0.064 & 0.066\end{array}$

Notes: Linear probability model of clearing the case with clustered (by series) standard errors in parentheses: ${ }^{* * *} \mathrm{p}<0.01,{ }^{* *} \mathrm{p}<0.05,{ }^{*} \mathrm{p}<0.1$. All regressions control for the same regressors used in Column 3 of Table 2. Fourier regressions control for 2 sine and 2 cosine functions of time, while the Event time regressions control for 12 interacted 30 minute event time dummies. 
Table 5: Individually Defined Shift change Period

\begin{tabular}{|c|c|c|c|c|}
\hline & (1) & $(2)$ & (3) & (4) \\
\hline & \multicolumn{4}{|c|}{ Cleared Robbery $(0 / 1)$} \\
\hline Turnover effects with & \multicolumn{2}{|c|}{ Fourier } & \multicolumn{2}{|c|}{ ' $\pm 1 h 15 m$} \\
\hline$\kappa=10 / 10$ & $\begin{array}{c}-0.051^{* * *} \\
(0.019)\end{array}$ & $\begin{array}{c}-0.050^{* * *} \\
(0.019)\end{array}$ & $\begin{array}{c}-0.046^{* *} \\
(0.021)\end{array}$ & $\begin{array}{c}-0.051^{* *} \\
(0.022)\end{array}$ \\
\hline$\kappa=11 / 10$ & $\begin{array}{c}-0.054^{* * *} \\
(0.019)\end{array}$ & $\begin{array}{c}-0.054^{* * *} \\
(0.019)\end{array}$ & $\begin{array}{c}-0.050^{* *} \\
(0.021)\end{array}$ & $\begin{array}{c}-0.054^{* * *} \\
(0.021)\end{array}$ \\
\hline$\kappa=12 / 10$ & $\begin{array}{c}-0.057^{* * *} \\
(0.018)\end{array}$ & $\begin{array}{c}-0.056^{* * *} \\
(0.018)\end{array}$ & $\begin{array}{c}-0.054^{* * *} \\
(0.020)\end{array}$ & $\begin{array}{c}-0.058^{* * *} \\
(0.020)\end{array}$ \\
\hline$\kappa=13 / 10$ & $\begin{array}{c}-0.056^{* * *} \\
(0.017)\end{array}$ & $\begin{array}{c}-0.055^{* * *} \\
(0.017)\end{array}$ & $\begin{array}{c}-0.052^{* * *} \\
(0.019)\end{array}$ & $\begin{array}{c}-0.056^{* * *} \\
(0.020)\end{array}$ \\
\hline$\kappa=14 / 10$ & $\begin{array}{c}-0.048^{* * *} \\
(0.017)\end{array}$ & $\begin{array}{c}-0.047^{* * *} \\
(0.017)\end{array}$ & $\begin{array}{c}-0.044^{* *} \\
(0.019)\end{array}$ & $\begin{array}{c}-0.047^{* *} \\
(0.019)\end{array}$ \\
\hline$\kappa=15 / 10$ & $\begin{array}{c}-0.049^{* * *} \\
(0.016)\end{array}$ & $\begin{array}{c}-0.048^{* * *} \\
(0.017)\end{array}$ & $\begin{array}{c}-0.046^{* *} \\
(0.018)\end{array}$ & $\begin{array}{c}-0.049 * * * \\
(0.019)\end{array}$ \\
\hline Other Xs & No & Yes & No & Yes \\
\hline Observations & 2167 & 2167 & 1316 & 1316 \\
\hline
\end{tabular}

Notes: Each coefficient measures the effect of a shift change period and refers to a different regression. These estimates exploit information on the exact location of the incident, and Google's predicted duration $\tau$ of driving from the Carabinieri or the Polizia headquarters to such location. Given that Google's estimated durations for Italy do not take traffic into account one can multiply such number by a constant that is larger or equal to 1 : $Y_{i, n}=\alpha+\delta I\left(\left|t_{i, n}-T\right| \leq \kappa \tau_{i, n}\right)+f\left(t_{i, n}\right) \epsilon_{i, n}$. Fourier regressions control for 2 sine and 2 cosine functions of time, while the $\pm 1 h 15 \mathrm{~m}$ regressions use only robberies that happen within 1 hour and 15 minutes from the shift changes (in line with the event study dummies). Linear probability model of clearing the case with clustered (by series) standard errors in parentheses: ${ }^{* * *} \mathrm{p}<0.01,{ }^{* *} \mathrm{p}<0.05,{ }^{*} \mathrm{p}<0.1$. 
Table 6: Spillovers

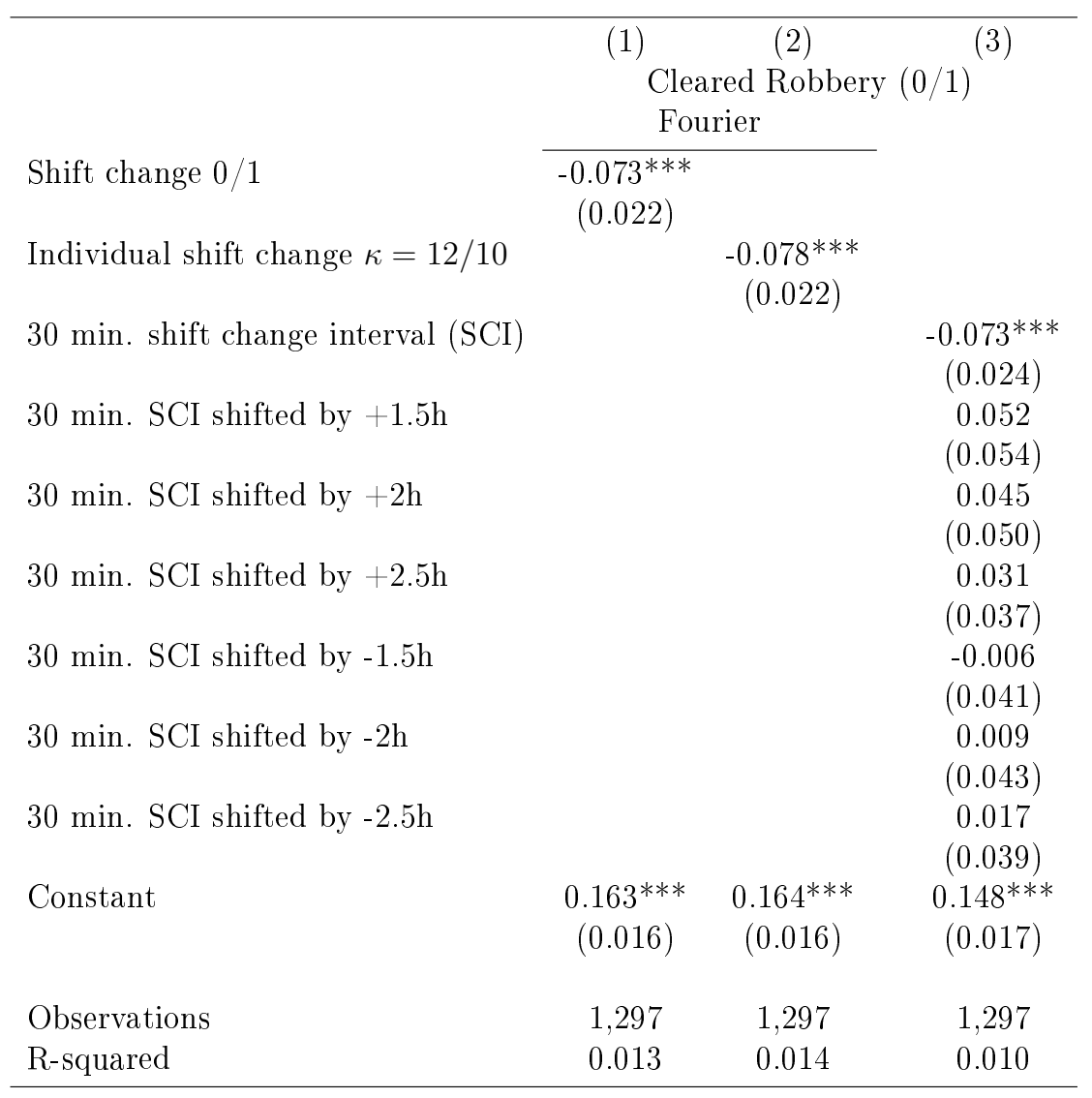

Notes: For each day and for each police force the sample is restricted to the very "first" robbery. See Table 2 for a description of the regressors.

Subsequent robberies are excluded. The Fourier regressions control for 2 sine and 2 cosine functions of time. Linear probability model of clearing the case with clustered (by series) standard errors in parentheses: $\mathrm{p}<0.01,{ }^{* *} \mathrm{p}<0.05,{ }^{*} \mathrm{p}<0.1$. 
Table 7: Number of Robberies

\begin{tabular}{|c|c|c|}
\hline & (1) & (2) \\
\hline & \multicolumn{2}{|c|}{ Number of Robberies } \\
\hline Shift change interval (SCI) & $\begin{array}{c}0.401^{* *} \\
(0.193)\end{array}$ & $\begin{array}{c}0.220 \\
(0.280)\end{array}$ \\
\hline SCI shifted by $+1.5 \mathrm{~h}$ & & $\begin{array}{c}-0.943^{* * *} \\
(0.190)\end{array}$ \\
\hline SCI shifted by $-1.5 \mathrm{~h}$ & & $\begin{array}{l}-0.228 \\
(0.163)\end{array}$ \\
\hline SCI shifted by $+2 \mathrm{~h}$ & & $\begin{array}{c}-0.591^{* * *} \\
(0.192)\end{array}$ \\
\hline SCI shifted by $-2 \mathrm{~h}$ & & $\begin{array}{c}-0.296^{*} \\
(0.170)\end{array}$ \\
\hline SCI shifted by $+2.5 \mathrm{~h}$ & & $\begin{array}{c}-0.419^{* *} \\
(0.172)\end{array}$ \\
\hline SCI shifted by $-2.5 \mathrm{~h}$ & & $\begin{array}{c}-0.678^{* * *} \\
(0.215)\end{array}$ \\
\hline Intervals interacted with: & \multicolumn{2}{|c|}{ Above Median Distance from HQ } \\
\hline Shift change interval (SCI) & $\begin{array}{c}0.166 \\
(0.219)\end{array}$ & $\begin{array}{l}0.158 \\
(0.362)\end{array}$ \\
\hline SCI shifted by $+1.5 \mathrm{~h}$ & & $\begin{array}{l}-0.111 \\
(0.251)\end{array}$ \\
\hline SCI shifted by $-1.5 \mathrm{~h}$ & & $\begin{array}{c}0.031 \\
(0.221)\end{array}$ \\
\hline SCI shifted by $+2 \mathrm{~h}$ & & $\begin{array}{l}-0.440 \\
(0.269)\end{array}$ \\
\hline SCI shifted by $-2 \mathrm{~h}$ & & $\begin{array}{l}-0.354 \\
(0.236)\end{array}$ \\
\hline SCI shifted by $+2.5 \mathrm{~h}$ & & $\begin{array}{l}-0.130 \\
(0.225)\end{array}$ \\
\hline SCI shifted by $-2.5 \mathrm{~h}$ & & $\begin{array}{c}0.363 \\
(0.280)\end{array}$ \\
\hline Above median distance from $\mathrm{HQ}$ & $\begin{array}{c}0.002 \\
(0.066)\end{array}$ & $\begin{array}{l}0.042 \\
(0.121)\end{array}$ \\
\hline Smooth Changeover & & \\
\hline Constant & $\begin{array}{c}-0.434^{* * *} \\
(0.068)\end{array}$ & $\begin{array}{c}0.473^{* * *} \\
(0.095)\end{array}$ \\
\hline Fourier series & Yes & No \\
\hline Within 1h15min from SC & No & No \\
\hline Observations & 1,656 & 1,656 \\
\hline
\end{tabular}

Notes: Poisson model of the number of robberies aggregated by 30 minute periods, by area (north-east, north-west, south), by median distance from the headquarters (HQ), and by shift change day type (from 1 to 3 ). Robust standard errors in parentheses: *** $\mathrm{p}<0.01$, ** $\mathrm{p}<0.05,{ }^{*} \mathrm{p}<0.1$. See Table 2 for a description of the regressors. 
Table 8: Balance Tests

\begin{tabular}{|c|c|c|c|c|}
\hline & \multicolumn{4}{|c|}{ Simple Differences } \\
\hline & \multicolumn{2}{|c|}{ Fourier } & \multicolumn{2}{|c|}{$' \pm 1 h 15 \mathrm{~min} \prime$} \\
\hline & $\widehat{\delta}$ & $\operatorname{se}(\widehat{\delta})$ & $\widehat{\delta}$ & $s e(\widehat{\delta})$ \\
\hline Loot in $€ 1,000$ & 0.091 & 0.681 & 0.075 & 0.720 \\
\hline Average age & -0.114 & 0.803 & 0.189 & 0.813 \\
\hline Ages are unknown & -0.009 & 0.019 & -0.017 & 0.018 \\
\hline Firearm $0 / 1$ & 0.049 & 0.031 & 0.052 & 0.031 \\
\hline At least one knife, but no firearm & 0.007 & 0.015 & 0.007 & 0.015 \\
\hline Number of robbers & 0.065 & 0.044 & 0.077 & 0.043 \\
\hline Some Italian & -0.003 & 0.025 & 0.011 & 0.025 \\
\hline Shops' closing time $0 / 1$ (90th percentile) & -0.161 & $0.024^{* * *}$ & -0.118 & $0.022^{* * *}$ \\
\hline Shops' closing time $0 / 1$ (maximum) & -0.121 & $0.018^{* * *}$ & -0.080 & $0.016^{* * *}$ \\
\hline Police $0 / 1$ & 0.010 & 0.026 & 0.017 & 0.025 \\
\hline Southern area & -0.069 & 0.029 & -0.055 & 0.029 \\
\hline \multirow[t]{2}{*}{ North-Western area } & -0.041 & 0.030 & -0.037 & 0.028 \\
\hline & \multicolumn{4}{|c|}{ Difference-in-Differences Based on Distance } \\
\hline Loot in $€ 1,000$ & -1.131 & 2.150 & -0.296 & 2.171 \\
\hline Average age & 3.012 & $1.395^{* *}$ & 3.279 & $1.372^{* *}$ \\
\hline Ages are unknown & -0.052 & $0.033^{* *}$ & -0.052 & 0.032 \\
\hline Firearm $0 / 1$ & -0.029 & 0.052 & -0.005 & 0.053 \\
\hline At least one knife, but no firearm & -0.051 & 0.036 & -0.073 & $0.035^{* *}$ \\
\hline Number of robbers & -0.115 & 0.077 & -0.124 & $0.075^{*}$ \\
\hline Some Italian & 0.050 & 0.047 & 0.068 & 0.045 \\
\hline Shops' closing time $0 / 1$ (90th percentile) & 0.088 & $0.046^{*}$ & 0.088 & $0.037^{* *}$ \\
\hline Shops' closing time 0/1 (maximum) & 0.049 & $0.035^{*}$ & 0.036 & 0.027 \\
\hline Police $0 / 1$ & 0.087 & 0.054 & 0.030 & 0.051 \\
\hline Southern area & -0.032 & 0.058 & -0.022 & 0.057 \\
\hline North-Western area & -0.022 & 0.062 & -0.012 & 0.059 \\
\hline
\end{tabular}

Notes: Each row corresponds to a different linear regression with the dependent variable listed on the left. The simple difference is the coefficient on the shift change dummy. The difference-in-differences is the coefficient on the interaction between the shift change dummy variable and the Above Median distance dummy variable. Fourier regressions control for 2 sine and 2 cosine functions of time, while the $\pm 1 \mathrm{~h} 15 \mathrm{~m}$ regressions use only robberies that happen within 1 hour and 15 minutes from the shift changes (in line with the event study dummies). ${ }^{* * *} \mathrm{p}<0.01,{ }^{* *} \mathrm{p}<0.05,{ }^{*} \mathrm{p}<0.1$. 


\section{A Appendix}

\section{A.1 Optimal choice of $k$}

To avoid overfitting one can either use the Akaike Information Criterion, which penalizes the likelihood function increasingly as more and more sine and cosine terms are added, or cross-validation, which rests on out of sample predictions. In particular, to predict the outcome of observation $i$ one uses all the other $N-1$ observations, repeating the exercise for all $N$ observations. 45 Table 10 shows that using this simple but slow "leave-one-out" cross-validation method, $k=2$ minimizes the cross-validation mean squared as well as the AIC objective function.

\section{A.2 Optimal timing of shift changes}

If robberies were the only crime, one would like to have shift changes when most businesses are closed and robberies are rare. The fraction of robberies that fall within a 30 minute shift change period can be drastically reduced from about 15 to about 2.5 percent by deferring all shift changes by just one and a half hours (1.30am, $8.30 \mathrm{am}, 2.30 \mathrm{pm}, 8.30 \mathrm{pm})$. One can estimate that the corresponding reduction in the expected number of robberies would be close to 6 percent. The change is small but could become much larger if criminals started exploiting these inefficiencies. 46

\section{A.3 Additional Tests for Deterrence}

\section{A.3.1 Correlation between ability and shift change targeting}

The first two tests use very detailed information on the timing of the robbery but no information about their evolution. Exploiting the panel structure of the data delivers additional tests for selection. These tests are designed to look for evidence of learning,

\footnotetext{
${ }^{45}$ See (Newey et al. 1990$)$ for a similar application of cross-validation.

${ }^{46} \mathrm{Such}$ change is equal to $\sum_{\tau=1}^{\infty} p_{t, 1}^{\tau}-\sum_{\tau=1}^{\infty} p_{t, 0}^{\tau}$, where $p_{t, i}=0.865+0.05 I\left(\left|t-T_{i}\right| \leq 15\right)$ represents the probability of success of a robbery, which depends on whether the robbery happened during a shift change period (the expected number of robberies for recurrent robbers, meaning robbers who will not stop robbing banks until caught, when their likelihood of success is $p$ is $\left.\sum_{\tau=1}^{\infty} p^{\tau}\right)$. Postponing the shift changes by 1.5 hours lowers the probability $P\left(\left|t-T_{i}\right| \leq 15\right)$ from 15 percent to 2.5 percent, which can be gauged using Table 7. For recurrent criminals the expected number of robberies would drop from 6 to 5.6. Given that there are about 260 first time robbers each year and that $1 / 3$ of these are recurrent offenders the reduction in the number of crimes per year would be close to 40 . Since the average haul is close to $€ 2,900$, one would reduce the total haul by about $€ 100,000$ a year.
} 
testing whether at least some robbers systematically or at least after some time target business during shift change periods.

One should expect more able robbers to be more likely to target businesses during shift change periods, and robbers who learn about any disturbance to the patrolling due to shift changes should become more and more likely to target such periods. The previous section has shown that variables that related to ability do not vary during shift changes, but the longitudinal aspect of the data allows one to measure ability in a different way. Recurrent robbers tend to be successful when they manage to behave unpredictably, limiting the effectiveness of predictive policing. Probably the most prominent unpredictability factor is the location of the robbery. Robbers who tend to choose business that are located close to each other are more likely to be caught. This can clearly be seen in the first panel of Figure 17. The Figure plots, for each of the 244 groups of robbers who performed at least 2 robberies, the total number of performed robberies against the average distance between subsequent robberies. Keeping in mind that recurrent robbers tend to rob businesses until they get caught the total number of business they manage to rob is a good proxy for their rate of success. Success is clearly positively correlated with the average distance between subsequent robbed businesses. Regressing the total number of robberies on the average distance one gets a coefficient equal to 0.53 with a standard error of 0.25 . Given that the average distance is equal to $2.45 \mathrm{~km}$ (1.5 miles) and the standard deviation is $1.63 \mathrm{~km}$ (1 mile), adding a standard deviation to the average distance increases success by almost an additional robbery ${ }^{47}$. Regressing the total number of robberies on the fraction of robberies that were done during shift change periods one again gets a coefficient which is positive and significant. A standard deviation increase $(0.20)$ in the fraction of robberies performed during shift change periods has almost the same effect as a standard deviation increase in the average distance. If choosing a shift change and choosing the distance between targets were deliberate choices and were both signaling a higher degree of ability, one would expect the two measures to be correlated with each other. Panel 3 of Figure 17 shows that this is not the case. The regression line is flat and if anything has a negative slope. 48

\footnotetext{
${ }^{47}$ Running a log-log regression the estimated elasticity is significantly different from 0 and larger than 20 percent.

${ }^{48}$ Inverting the regression the results are the same, there is no significance and the slope is negative.
} 


\section{A.3.2 Learning about shift changes}

It could still be that robbers learn over time about the opportunities that arises during shift change. If this were the case one would expect these robbers to start targeting such periods. The easiest way to see this is to observe the evolution of the time chosen by the individual offenders across robberies. The 9 panels of Figure 19 show the evolution of the time chosen by the 9 most prolific groups of robbers ${ }^{49}$ Not only is there little evidence of convergence (learning), but for 7 out of 9 most prolific offenders less than one in three robbery falls inside a turnover period (individually defined as in Table 5 with $\kappa=1.2$ ).

In order to see whether the persistence in the chosen time of the day that is visible around shift changes represents an anomaly, one can estimate whether the probability of organizing a robbery during an event time period depends on having organized the previous robbery during the same event time period. Using once again a linear probability model, I regress the event time dummy $\Gamma_{i, n}^{c}$ on the event time dummy in the previous robbery $\Gamma_{i, n-1}^{c}$. Given the autoregressive nature of the regression I do not control for the Fourier series, but in line with the event studies, I select the sample to be within 1 hour and 15 minutes around the chosen event time. Figure 18 shows that the shift changes (event time 0 ) do not show autoregressive coefficients that are any different from the other event times.

Finally, another simple way to directly test whether the results are driven by selection is to compute the shift change effect on the sample of offenders who have never before organized a robbery during a shift change. For these robbers a shift change effect is less likely to be the product of ability. Table 11 shows that there is no evidence that with this sample selection the shift change effects disappear, no matter whether the shift change periods are computed using the 30 minute approximation, or they are computed using the individual information on the distance from the headquarters. This indicates that as long as for most robbers the learning is not sudden and discontinuous, selection does not explain the differences in clearance rates.

\footnotetext{
${ }^{49}$ The 9 groups of robbers organize about 15 percent of all robberies, and all the previous results are robust to the exclusion of these most prolific groups of robbers.
} 

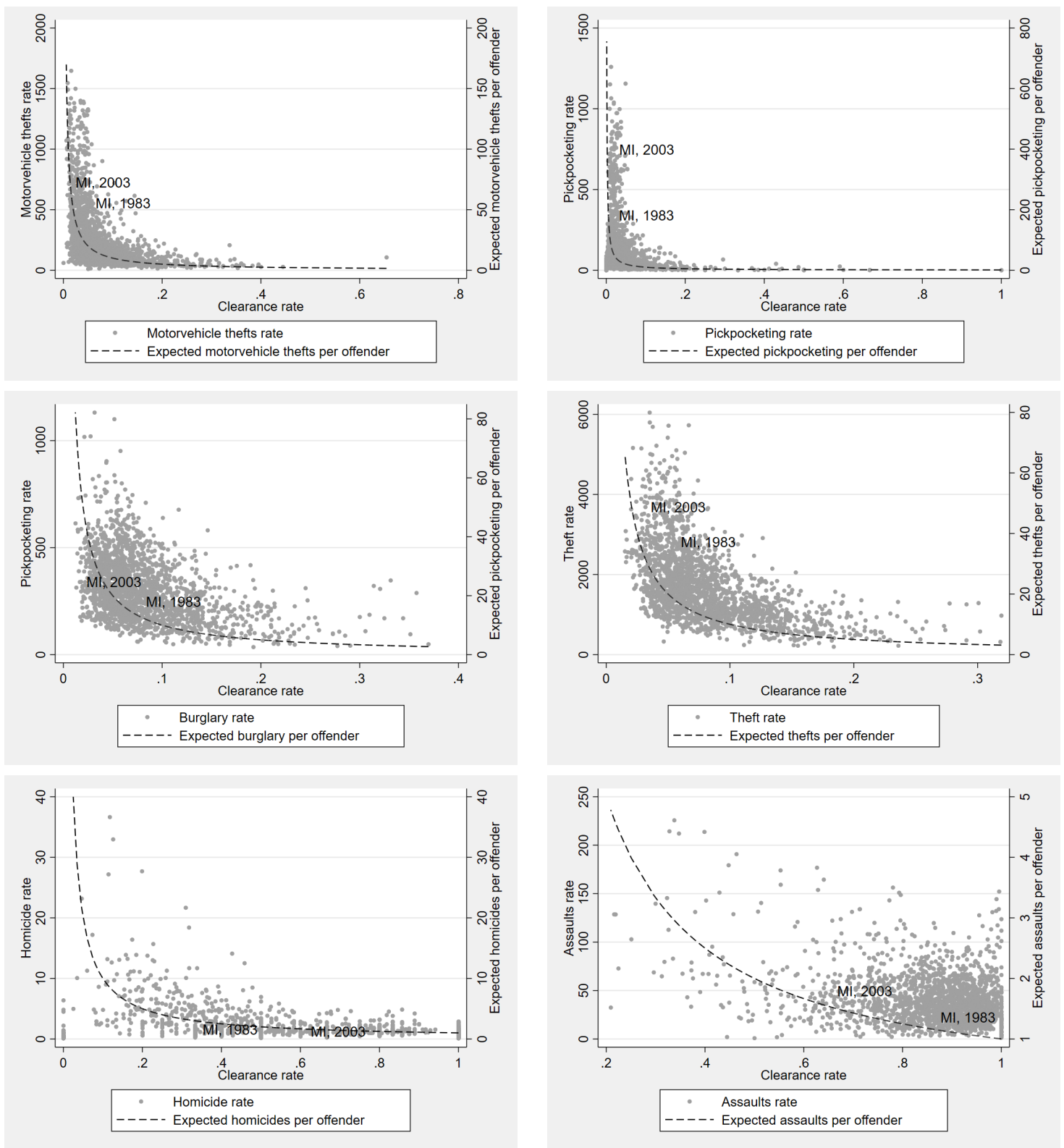

Figure 11: Aggregate Crime Rates and the Corresponding Clearance Rates

Notes: The dashed line simply plots 1/c. Based on 103 Italian provinces between 1983 and 2003. 


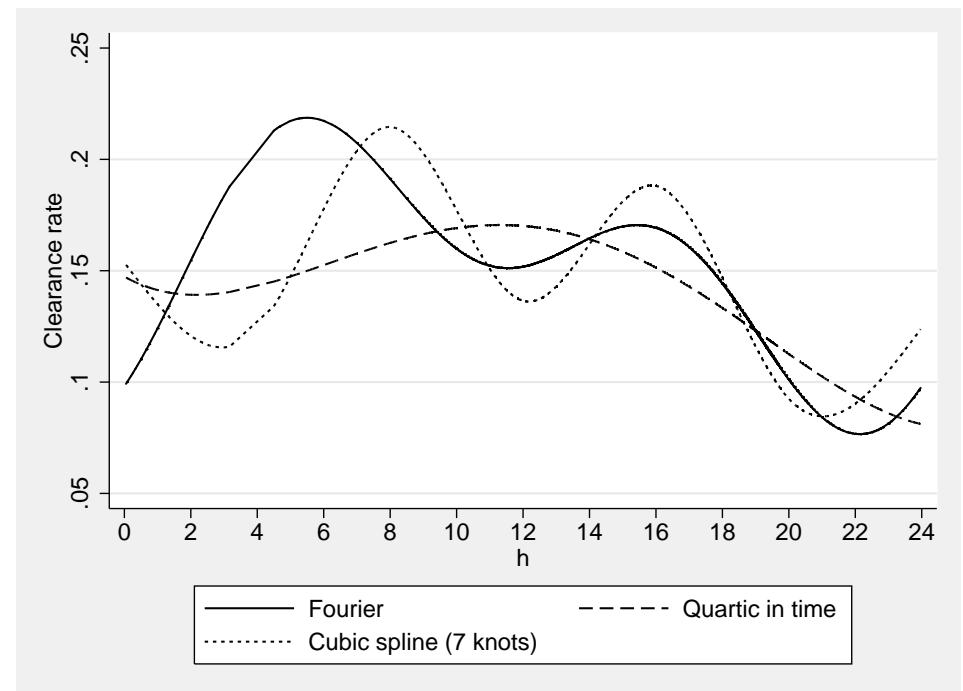

Figure 12: Predicted Clearance Rates

Notes: Clearance rates based on different smoothers. The Fourier series uses with 2 sine and 2 cosine terms (optimal based on cross-validation).

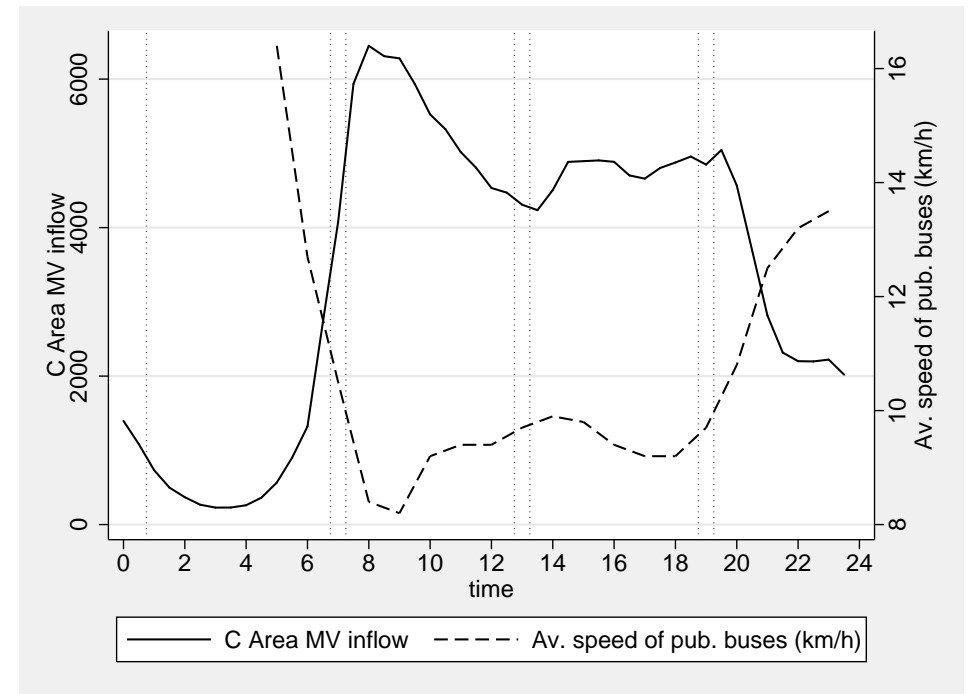

Figure 13: Traffic in Milan

Notes: Average speed of public buses in the city center (right axis) and the inflow of cars in the city center (Area $C$, left axis). Source: http://www.amat-mi.it/. 

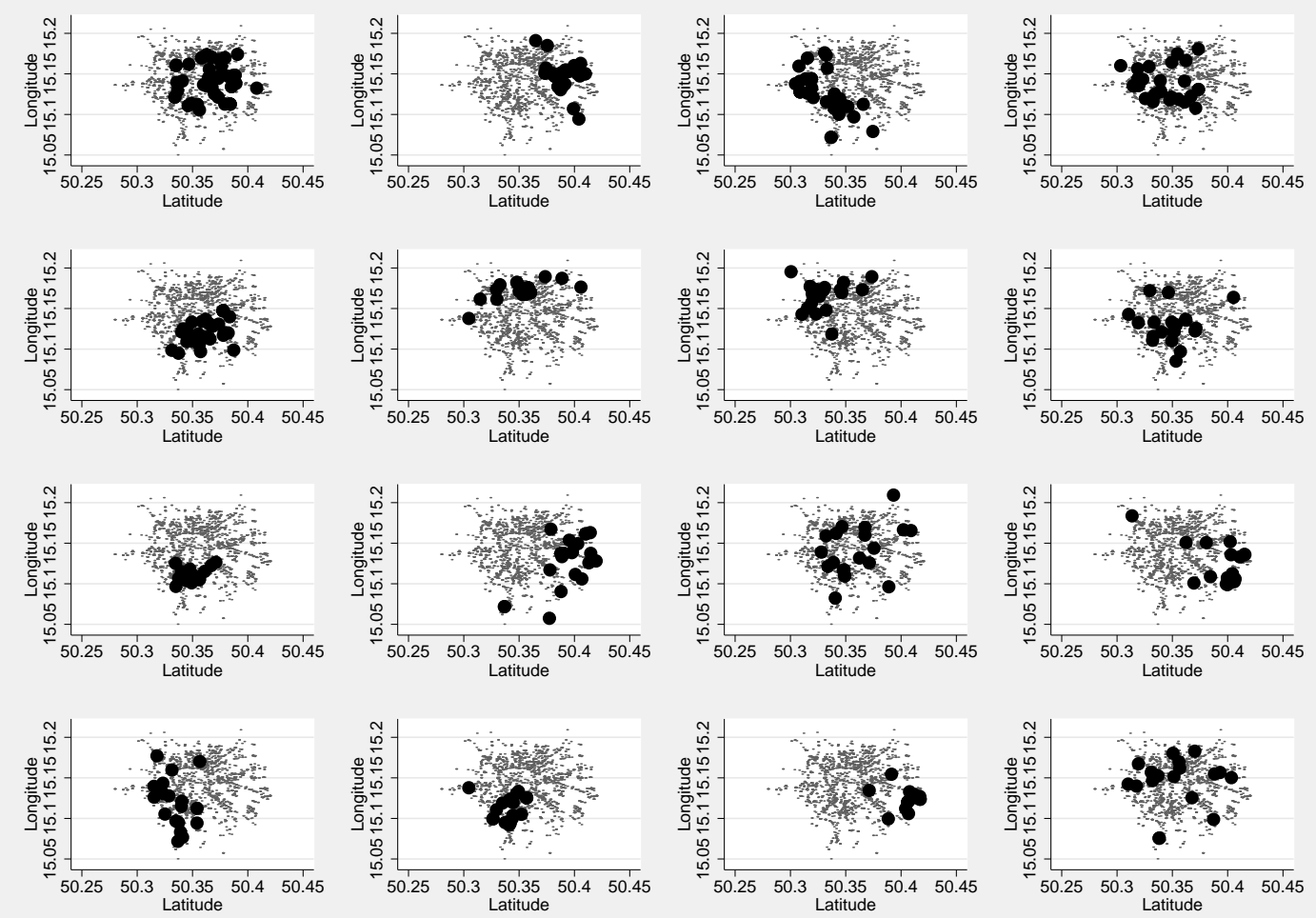

Figure 14: Geographic Distribution of Robberies by Criminal Group

Notes: The plots are restricted to those groups who performed at least 15 robberies. In each plot the large black dots indicate the chosen victims by a separate group of robbers. In order to visualize the degree of clustering, the small grey dots represent all the other robberies. 

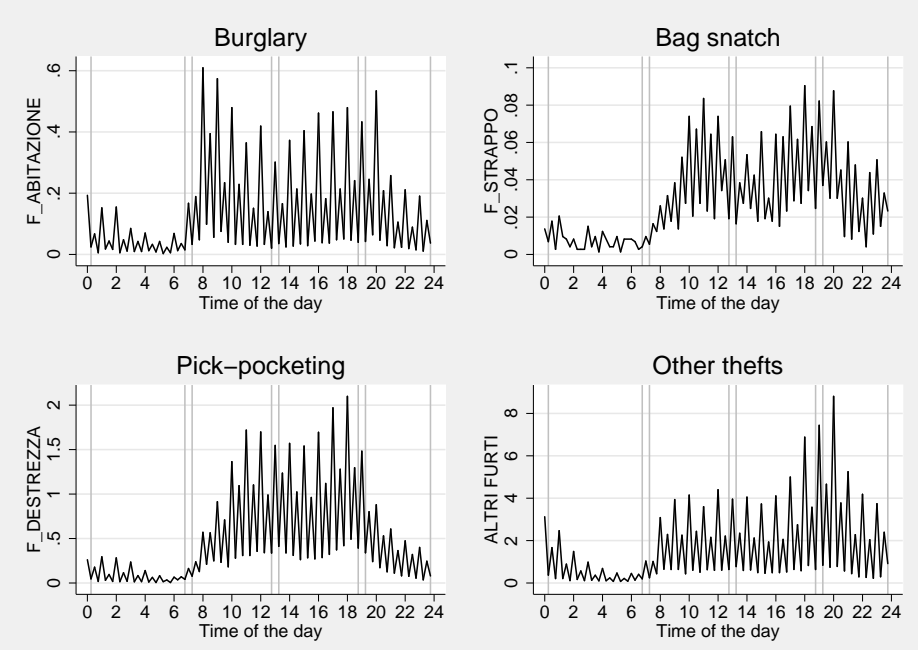

Figure 15: Average Number of Daily Thefts in 15 Minute Intervals

Notes: Based on 93 percent of all thefts that occurred in Milan between 2009 and 2010. This figure corresponds to Figure 6 , but before smoothing the series to reduce heaping.

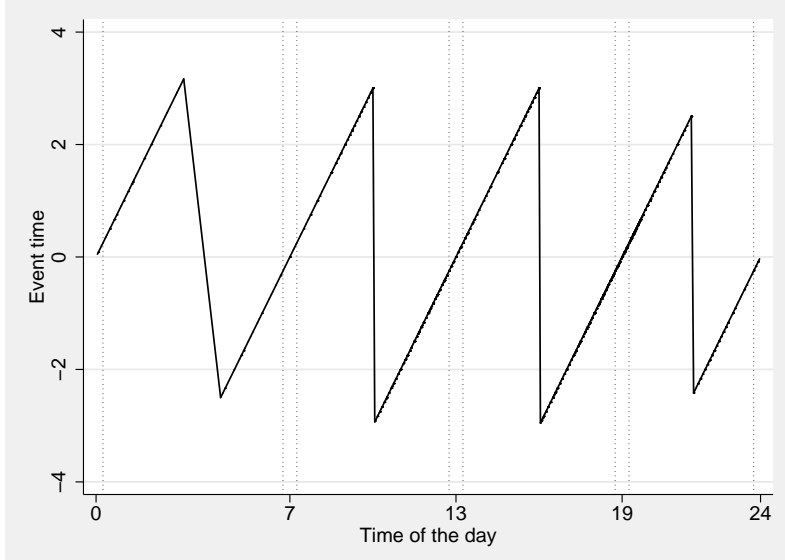

Figure 16: Event time vs. Time of the Day

Notes: The figures show the observed relationship between time of the day and event time. 


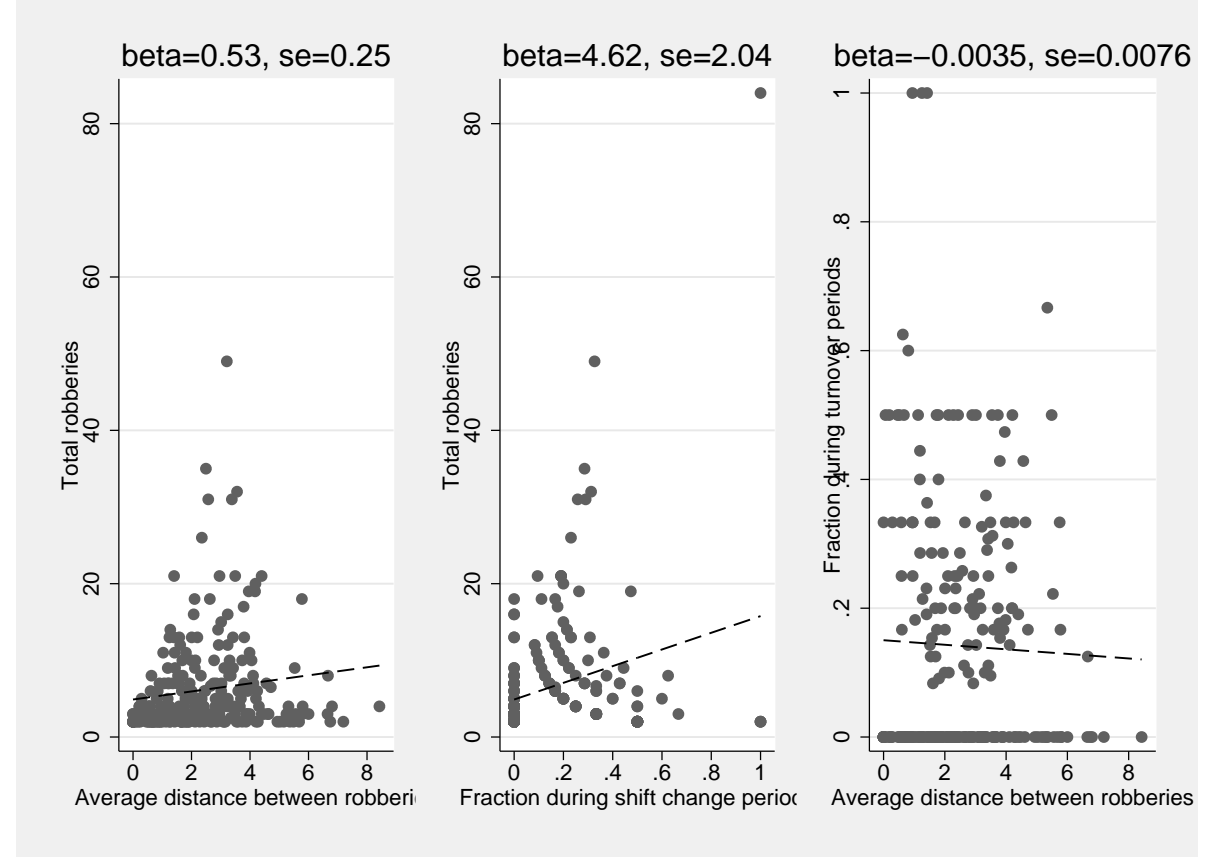

Figure 17: Unpredictability, Success, and Shift change Periods

Notes: Each plot is based on averages over 244 individual robbers or groups of robbers who performed at least two robberies. Distances are air travel distances in kilometers computed using Pythagoras theorem. The average distance is $2.45 \mathrm{~km}(\mathrm{sd}=1.64)$, the average total number of robberies is 6.15 $(\mathrm{sd}=6.34)$ and the fraction of shift change periods is $0.14(\mathrm{sd}=0.20)$. 

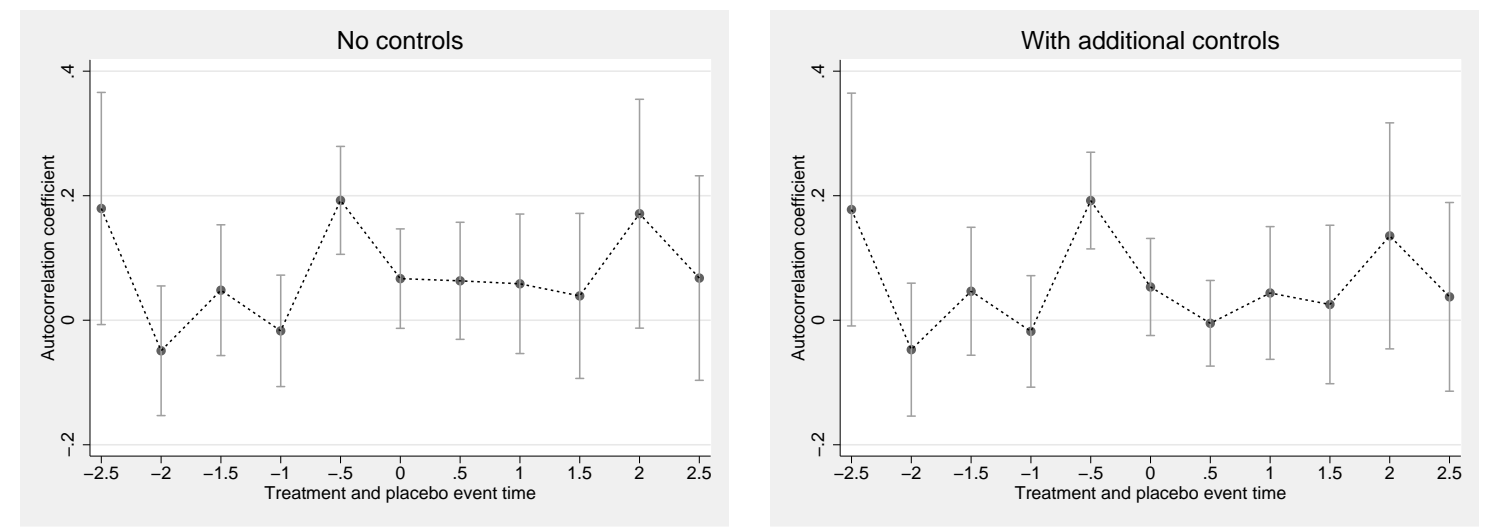

Figure 18: Autocorrelation of Treatment and Placebo Shift Changes

Notes: Each dot represents a different autocorrelation coefficient between selecting a shift change or a placebo shift change and having selected one in the previous robbery. The corresponding vertical lines measure the 95 percent confidence intervals (based on clustered, by series, standard errors). Event time measures the time (in hours) from shift changes ranging from -2.5 hours to +2.5 hours. The estimate corresponding to the event time 0 corresponds to the correct shift change (centered at 12 am, 7 am, 1 $\mathrm{pm}, 7 \mathrm{pm}$ ). There is one estimate for each placebo (event time $\neq 0$ ) shift change shifted by 30 minutes forward or backward. In line with the event study, each sample is restricted to 1 hour and 15 minutes before and after the shift change (placebo or real). The autocorrelation coefficients in the right panel are conditional on the shops' closing time dummies. 

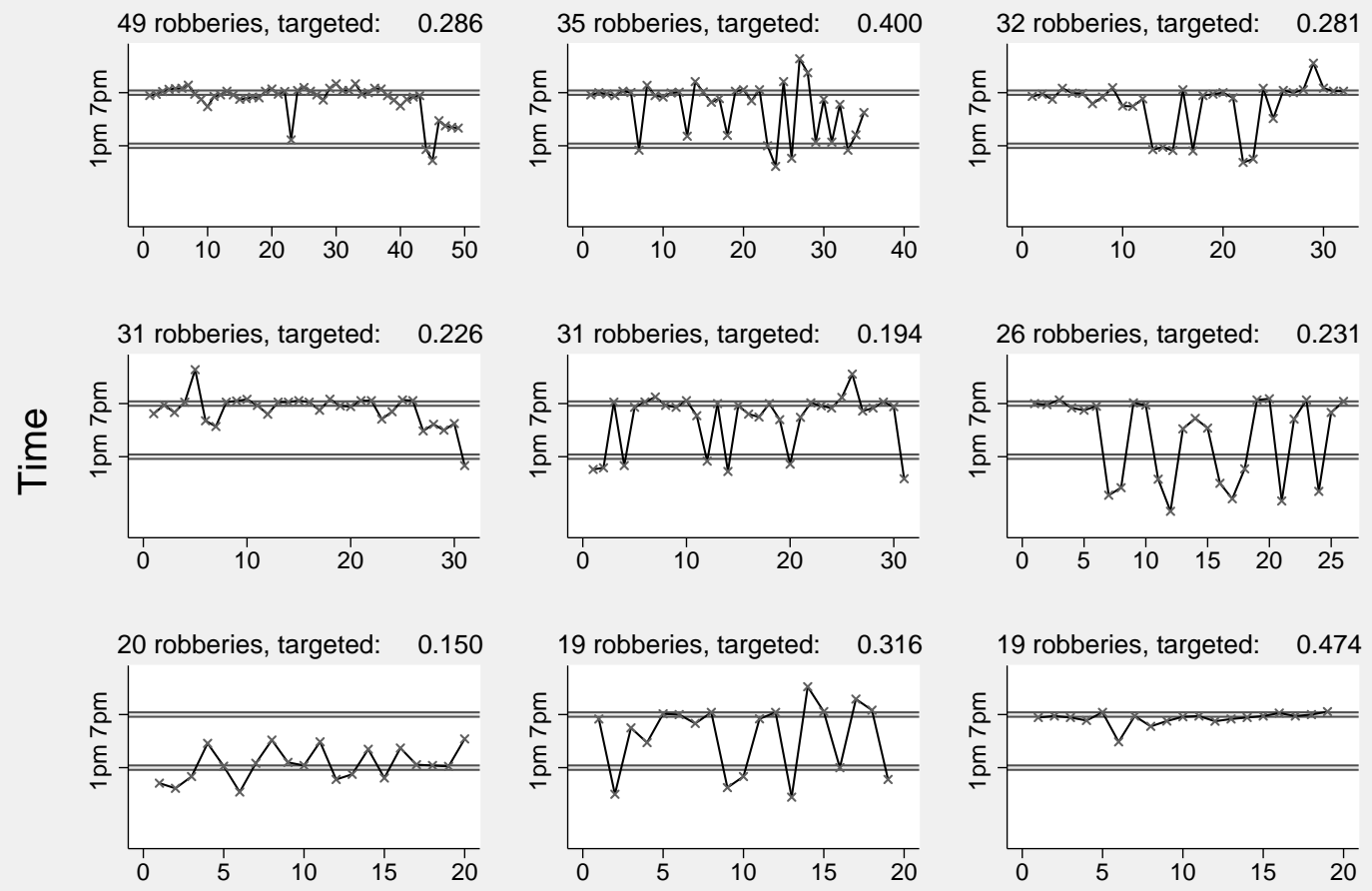

Number of the series

Figure 19: Individual Time Patterns

Notes: Horizontal lines indicate the 30 minute shift change periods around shifts. 
Table 9: Closing Time of Businesses

\begin{tabular}{lccc}
\hline & 90 th percentile & maximum & Freq. \\
Apparel shops & $7: 40 \mathrm{pm}$ & $8: 10 \mathrm{pm}$ & 49 \\
Betting shops & $8: 02 \mathrm{pm}$ & $11: 00 \mathrm{pm}$ & 50 \\
Travel agencies & $7: 45 \mathrm{pm}$ & $7: 45 \mathrm{pm}$ & 10 \\
Groceries & $7: 45 \mathrm{pm}$ & $7: 45 \mathrm{pm}$ & 9 \\
Others & $8: 00 \mathrm{pm}$ & $11: 45 \mathrm{pm}$ & 202 \\
Banks & $3: 45 \mathrm{pm}$ & $6: 10 \mathrm{pm}$ & 237 \\
Cafes & $9: 17 \mathrm{pm}$ & $11: 30 \mathrm{pm}$ & 68 \\
Gas stations & $7: 55 \mathrm{pm}$ & $8: 20 \mathrm{pm}$ & 31 \\
Newspaper stands & $8: 10 \mathrm{pm}$ & $11: 27 \mathrm{pm}$ & 47 \\
Estheticians & $9: 20 \mathrm{pm}$ & $10: 30 \mathrm{pm}$ & 12 \\
Pharmacies & $8: 00 \mathrm{pm}$ & $11: 55 \mathrm{pm}$ & 763 \\
Jewelers & $6: 32 \mathrm{pm}$ & $7: 17 \mathrm{pm}$ & 24 \\
Hotels & $11: 00 \mathrm{pm}$ & $11: 46 \mathrm{pm}$ & 28 \\
Bakeries & $7: 10 \mathrm{pm}$ & $7: 30 \mathrm{pm}$ & 11 \\
Phone centers & $10: 35 \mathrm{pm}$ & $11: 06 \mathrm{pm}$ & 24 \\
Drugstores & $7: 45 \mathrm{pm}$ & $7: 45 \mathrm{pm}$ & 26 \\
Restaurants & $11: 46 \mathrm{pm}$ & $11: 55 \mathrm{pm}$ & 33 \\
Supermarkets & $8: 00 \mathrm{pm}$ & $10: 10 \mathrm{pm}$ & 348 \\
Tobacco & $8: 35 \mathrm{pm}$ & $10: 40 \mathrm{pm}$ & 59 \\
Taxi & $10: 50 \mathrm{pm}$ & $11: 50 \mathrm{pm}$ & 14 \\
Phone shops & $9: 45 \mathrm{pm}$ & $10: 15 \mathrm{pm}$ & 15 \\
Postal office & $4: 05 \mathrm{pm}$ & $7: 10 \mathrm{pm}$ & 23 \\
Video rentals & $11: 18 \mathrm{pm}$ & $11: 58 \mathrm{pm}$ & 61 \\
\hline
\end{tabular}


Table 10: Choice of Sine and Cosine Terms

\begin{tabular}{llcccccc}
\hline $\sin / \cos$ terms & $\delta$ & se & log-likelihood & df & CV MSE & AIC & BIC \\
\hline 1 & -0.052 & $0.019^{* * *}$ & -762.825 & 6 & $11.899 \%$ & 1537.649 & 1571.736 \\
2 & -0.049 & $0.019^{* * *}$ & -759.917 & 8 & $11.891 \%$ & 1535.834 & 1581.283 \\
3 & -0.040 & $0.019^{* *}$ & -758.308 & 10 & $11.897 \%$ & 1536.617 & 1593.428 \\
4 & -0.034 & 0.022 & -758.074 & 12 & $11.919 \%$ & 1540.148 & 1608.321 \\
5 & -0.036 & 0.023 & -757.456 & 14 & $11.937 \%$ & 1542.913 & 1622.448 \\
6 & -0.048 & $0.023^{* *}$ & -753.273 & 16 & $11.914 \%$ & 1538.545 & 1629.443 \\
7 & -0.035 & 0.024 & -751.095 & 18 & $11.915 \%$ & 1538.189 & 1640.449 \\
8 & -0.029 & 0.025 & -750.634 & 20 & $11.935 \%$ & 1541.268 & 1654.891 \\
9 & -0.029 & 0.025 & -750.615 & 22 & $11.960 \%$ & 1545.229 & 1670.213 \\
\hline
\end{tabular}

Notes: Each line represents a different regression. $\delta$ measures the shift change effect, and "se" is the corresponding standard error. Linear probability model of clearing the case with clustered (by series) standard errors: *** $\mathrm{p}<0.01, * *$ $\mathrm{p}<0.05,{ }^{*} \mathrm{p}<0.1$. "df" measures the degree of freedom, CV MSE the mean squared error in a "leave one out" cross-validation, and AIC the Akaike Information Criteria.

Table 11: Shift Change Effects Among Shift Change Entrants

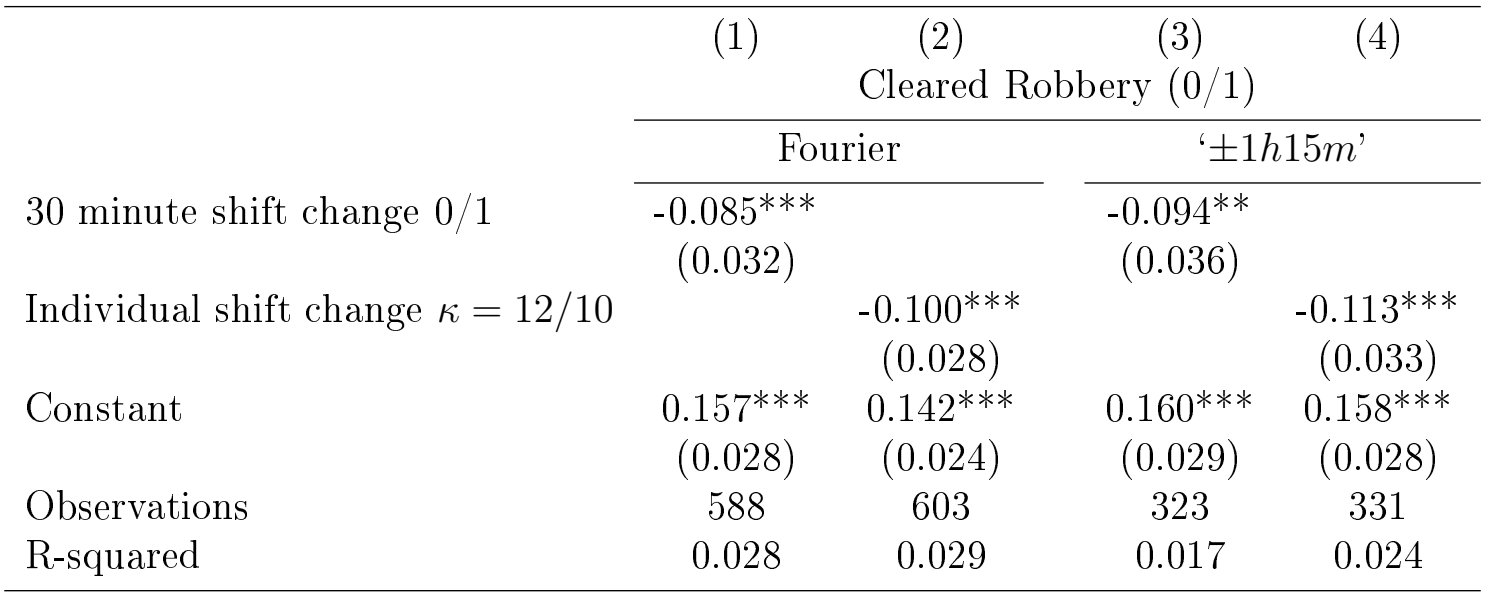

Notes: The sample is restricted to robbers with some experience (at least one robbery) who never before organized a robbery during a turnover period. Turnover periods are defined using the 30 minute intervals (Columns 1 and 3) or using the individual measure with $\kappa=12 / 10$ used in Table 5. The identification of the shift change effect is based on robbers who for the first time fall into a shift change period. Fourier regressions control for 2 sine and 2 cosine functions of time, while the $\pm 1 \mathrm{~h} 15 \mathrm{~m}$ regressions use only robberies that happen within 1 hour and 15 minutes from the shift changes (in line with the event study dummies). *** $\mathrm{p}<0.01,{ }^{* *} \mathrm{p}<0.05, * \mathrm{p}<0.1$. 